\title{
Distinct neural representations for prosocial and self-benefitting effort
}

Patricia L. Lockwood ${ }^{a, b, c, d, e^{*}}$, Marco Wittmannn, ${ }^{c, d}$, Hamed Nilid, Mona Matsumoto-Ryan ${ }^{c}$, Ayat Abdurahman, ${ }^{c, f}$, Jo Cutlera,b,c, Masud Husain ${ }^{a, b}$, Matthew A. J. Apps ${ }^{a, b, c, e}$

aCentre for Human Brain Health, School of Psychology, University of Birmingham

bInstitute for Mental Health, School of Psychology, University of Birmingham

'Department of Experimental Psychology, University of Oxford

dWellcome Centre for Integrative Neuroimaging, University of Oxford

eChrist Church, University of Oxford

fDepartment of Psychology, University of Cambridge

${ }^{*}$ Correspondence should be addressed to:

Patricia L. Lockwood, Centre for Human Brain Health, University of Birmingham, United Kingdom. E-mail: p.l.lockwood@bham.ac.uk 


\begin{abstract}
Prosocial behaviours - actions that benefit others - are central to individual and societal wellbeing. Most prosocial acts are effortful. Yet, how the brain encodes effort costs when actions benefit others is unknown. Here, using a combination of multivariate representational similarity analysis and model-based univariate analysis during $\mathrm{fMRI}$, we reveal how the costs of prosocial efforts are processed. Strikingly, we identified a unique neural signature of effort in the anterior cingulate gyrus for prosocial acts both when choosing to help others and when exerting force for their benefit. This pattern was absent for similar self-benefitting behaviour and correlated with individual levels of empathy. In contrast, the ventral tegmental area and the ventral insula signalled subjective value preferentially when choosing whether to exert effort to benefit oneself. These findings demonstrate partially distinct brain areas guide the evaluation and exertion of effort costs when acts are prosocial or self-benefitting.
\end{abstract}




\section{Main}

1 From holding open a door for a stranger to volunteering for a local charity, humans often make decisions to incur costs to benefit others ${ }^{1,2}$. Such 'prosocial' behaviours are vital for maintaining individual physical ${ }^{3}$ and mental health ${ }^{4}$ and are positively correlated with societal economic success ${ }^{5}$. However, whilst a plethora of research has begun to probe the psychological and neural mechanisms underlying how people make decisions about whether to donate to charity or share money, much of this work overlooks a key component: effort6-9. In order to behave prosocially, we have to decide whether we are willing to exert effort to help, and once committed, to energise our actions ${ }^{9,10}$. However, how the brain represents the effort of a prosocial act, and whether this representation is distinct from self-benefitting acts, is unknown. Uncovering such specificity is critical for connecting computational and neural levels of explanation of social behaviour ${ }^{11-13}$.

Effort is typically considered as costly and aversive ${ }^{14-17}$. If two courses of action are associated with the same rewarding outcome, most individuals will choose the course that requires less effort. This phenomenon, referred to as effort-discounting, relies on computations in which rewards are subjectively devalued by the cost of exerting effort ${ }^{9,18-20}$. As such, people appear only to exert effort when it is considered 'worth it' for the rewards that can be obtained. Research across species has begun to identify the anatomy engaged during such computations. Activity in the dorsal anterior cingulate cortex (dACC)/dorsomedial prefrontal cortex (dmPFC) and anterior insula (AI) has consistently been shown to covary with the magnitude of rewards and level of task difficulty, both prior to and during the performance of a task ${ }^{18,21-25}$. In addition, activity in these regions tracks subjective value during effort-based decisions ${ }^{18,24-31}$. Lesions to these brain areas have been linked to reductions in motivated behaviour and to a reduced willingness to exert effort ${ }^{32}$. Such findings implicate the $\mathrm{dACC} / \mathrm{dmPFC}$ and $\mathrm{Al}$ as crucially engaged both when deciding whether to exert effort for reward, and when energising effortful processes.

However, existing work has typically only examined self-benefitting behaviours, where the effort is exerted to obtain rewards for one's own benefit. Yet, the cost of effort may be different when it comes to prosocial acts. Lockwood and colleagues ${ }^{9}$ required participants to make decisions about whether they would rather take a rest for small reward (1 credit) or exert 30 physical effort (30-70\% of their max grip strength) to obtain higher rewards (2-10 credits). On 31 half the trials participants chose whether to exert the effort to obtain credits for themselves, 32 but on the other half the credits were delivered to an anonymous other person. Whilst people 
bioRxiv preprint doi: https://doi.org/10.1101/2021.09.27.461936; this version posted September 28, 2021. The copyright holder for this preprint (which was not certified by peer review) is the author/funder, who has granted bioRxiv a license to display the preprint in perpetuity. It is made available under aCC-BY 4.0 International license.

were willing to exert effort to obtain rewards for others, the effort cost was evaluated to be greater than when the effort was self-benefitting, and participants were less willing to exert higher levels of effort for prosocial acts $8,9,33,34$. This differential weighting of effort costs into valuations raises the possibility that partially distinct neural mechanisms may guide decisions of whether to exert effort for prosocial and self-benefitting behaviours.

Whilst there is limited research examining the neural mechanisms underlying prosocial effort, studies examining how we vicariously process others rewards or efforts implicate a potentially 'socially' specialised system ${ }^{35,36}$. Studies in which self and other trials are separated in the design, allow questions about social specificity to be addressed ${ }^{12}$. In such studies a sub-region of the anterior cingulate cortex lying in the gyrus (ACCg) has been implicated in processing social information. Neurophysiological recordings in monkeys indicate that the ACCg contains a higher proportion of neurons that signal exclusively when another, not oneself, receives rewards compared to other frontal cortex regions ${ }^{37}$. The BOLD response in this region varies as a function of the vicarious net-value of other people exerting effort, the probability and outcome of another person receiving a reward, and tracks learning about others' ownership, but does not process similar information about one's own effort, ownership or reward ${ }^{38-41}$. Activity in ACCg has also been shown to correlate with self-reported individual differences in empathy, an affective process closely linked to motivating prosocial behaviours ${ }^{36,42,43}$. In addition, activity in a connected portion of the temporo-parietal junction (TPJ) has long been implicated in social cognition and prosocial behaviour, and encodes effort costs differently when behaviours switch from being cooperative to competitive $\mathrm{e}^{44-50}$. Thus a partially specialised neural circuit, comprising the ACCg and TPJ, may be engaged when deciding whether to exert effort to benefit others and applying the energy required.

Here, to address the question of whether prosocial efforts are processed distinctly from selfbenefitting ones, participants completed a physical effort task ${ }^{9}$ where self-benefitting and prosocial decisions were dissociated. People chose between a work option and rest option on each trial whilst undergoing functional magnetic resonance imaging (fMRI). Half of the trials were self-benefitting, where they chose whether to exert effort to obtain rewards for themselves (Self), whilst the other half were prosocial - where the participant chose whether to exert effort to obtain rewards for an anonymous other person (Other, see Methods and Figure S1). If they chose to work, they needed to execute the required force to obtain that reward. Using this design, we could examine activity time-locked to the points in the trial where people made a decision to work or rest and responses during the exertion of force (Figure 1A). Participants also completed a self-report assessment of individual differences in empathy. 
bioRxiv preprint doi: https://doi.org/10.1101/2021.09.27.461936; this version posted September 28, 2021. The copyright holder for this preprint (which was not certified by peer review) is the author/funder, who has granted bioRxiv a license to display the preprint in perpetuity. It is made available under aCC-BY 4.0 International license.

We used a combination of parametric (and model-based) univariate analyses, as well as model-based, multivariate Representational Similarity Analysis (RSA). RSA allowed us to directly test for social and self specific representations of effort when deciding whether to benefit self and other, as well as subjective value and reward. It also enabled us to test for novel neural patterns that cannot be revealed from a purely univariate analysis, but that may be crucial for prosocial behaviour ${ }^{51}$.

We show a distinct multivariate pattern of effort in the ACCg when deciding whether to act prosocially, and that activity in this region scales parametrically with the force required during exertion into prosocial but not self-benefitting acts. This pattern correlated with individual differences in self-reported affective empathy, with those highest in empathy having more distinct patterns of prosocial effort in ACCg. A domain-general set of regions in the $\mathrm{Al}$ and $\mathrm{dACC} / \mathrm{dmPFC}$ signalled multivariate and univariate representations of subjective value for self and other. In contrast, a ventral portion of the mid-insula and the ventral tegmental area carried self-benefitting univariate and multivariate representations of subjective value, respectively. Together these results reveal partially specialised neural mechanisms for prosocial and selfbenefitting efforts. These findings are important for our understanding and fostering of motivated behaviour and particularly effortful prosocial behaviours.

A

Prosocial and self-benefitting effort-based decision-making

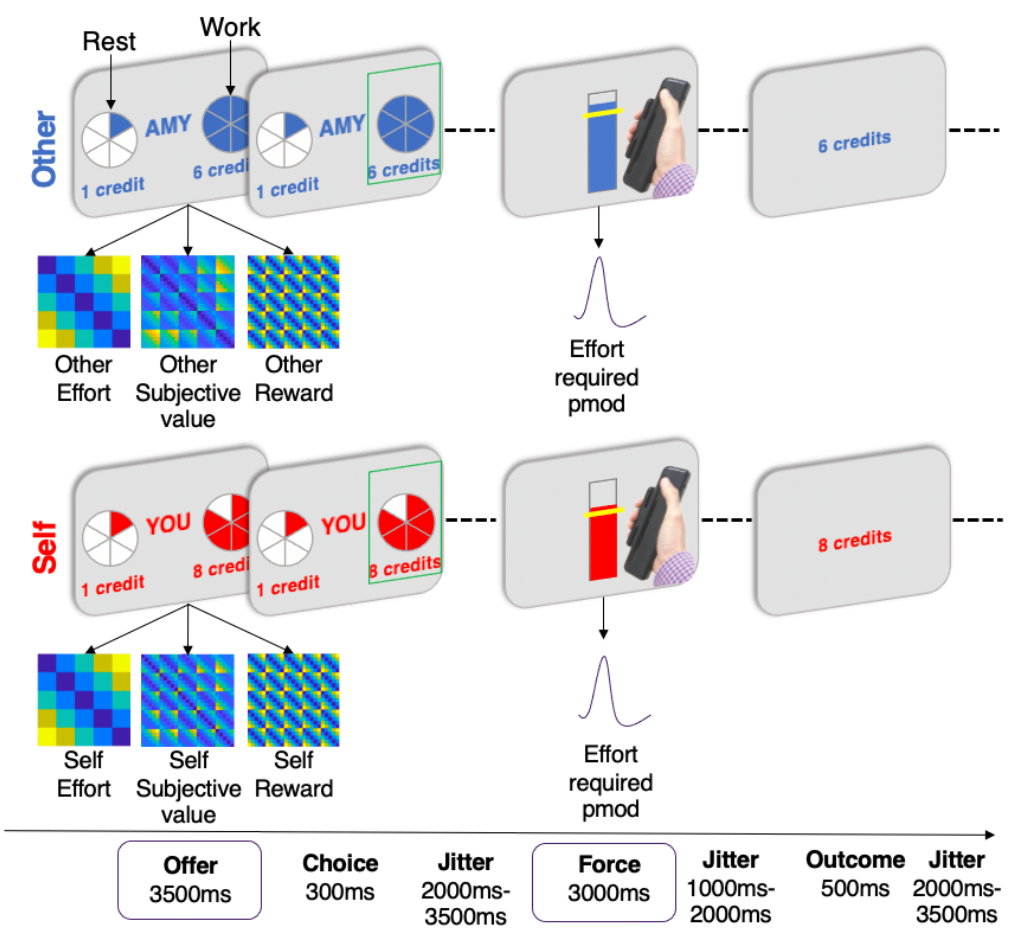

B Model representational dissimilarity matrices (RDMs) at Offer
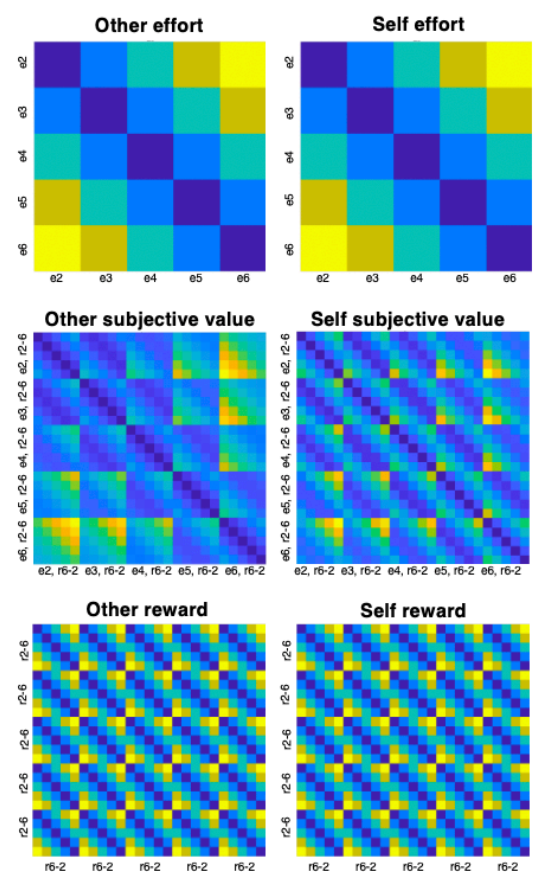

Self reward

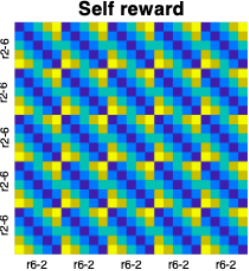


bioRxiv preprint doi: https://doi.org/10.1101/2021.09.27.461936; this version posted September 28, 2021. The copyright holder for this preprint (which was not certified by peer review) is the author/funder, who has granted bioRxiv a license to display the preprint in perpetuity. It is made available under aCC-BY 4.0 International license.

Figure 1. Prosocial and self-benefitting effort decision-making task and model RDMs. (A) Before undergoing fMRI participants were instructed to squeeze as hard as they could to measure their Maximum Voluntary Contraction (MVC) on a handheld dynamometer to threshold each effort level to their own grip strength. After thresholding and practice, participants were presented on each trial with a choice between a rest option, which required no effort ( $0 \%$ MVC, corresponding to one segment of the pie chart) for a low reward of 1 credit, and a work option, which required more effort $(30 \%-70 \%$ MVC, corresponding to 2-6 segments in the pie chart) yet also generated more reward (2-10 credits). The offered reward and effort levels were orthogonal in the design. After making their selection, participants then had to exert the required force to the correct degree to receive the reward. Visual feedback of the amount of force used was displayed on the screen. Participants were informed that they would have to reach the required force level (marked by the yellow line) for at least $1 \mathrm{~s}$ out of a $3 s$ window. Participants then saw the outcome that corresponded to the offer they had chosen, unless they were unsuccessful, in which case " 0 credits" was displayed. Crucially, on Self trials, participants made the choice, exerted the effort, and received the reward themselves, whereas on Other trials ("AMY" in this example), participants made the choice and exerted the effort, but the other participant received the reward. Participants completed 200 trials, 100 with outcomes for themselves and 100 with outcomes for the other person. Self and other trials were interleaved (see Methods). (B) Six $25 \times 25$ (5 effort and 5 reward levels) model representational dissimilarity matrices (RDMs) were constructed at the offer stage to analyse activity during effort-based decisions separately for the self and other conditions. These coded for different task features in multivariate space. For the effort model RDMs, this was the Euclidean distance between effort levels on offer. For the subjective value RDMs, this was the Euclidean distance between subjective values of offers based on the winning computational model with separate discount parameters $(K)$ for self and other trials. Each participant's individual $K$ parameter was used. For the reward RDMs this was the Euclidean distance between reward levels on offer. To examine activity during the energisation of actions (force period), univariate parametric modulators (pmod, panel a) of the effort required on each trial were fitted to the onset of the force period; e: effort level, $r$ : reward level. Yellow colours show conditions are more dissimilar whereas dark blue colours show conditions are more similar in terms of the Euclidean distance between conditions.

\section{Results}

\section{People discount rewards by effort more strongly for others than for self}

We analysed how peoples' decisions to select the work offer over 'rest' were affected by the recipient (self or other), effort required, reward on offer, and whether participants treated prosocial decisions as distinct from self-benefitting ones (recipient). To do so we ran a generalised linear mixed-effects model (GLMM; see Methods). We observed a significant recipient ${ }^{*}$ effort ${ }^{\star}$ reward interaction (odds ratio $(\mathrm{OR})=0.81,95 \%$ confidence interval $=[0.69$, 0.95], $p=0.009$ ), showing that people were less willing to help others at higher effort and lower reward levels. We also observed significant interactions between recipient and reward $(\mathrm{OR}=1.71$ [1.44, 2.04], $p=0.001)$, effort and reward $(\mathrm{OR}=1.23$ [1.11, 1.36], $p=0.001)$, and main effects of recipient, effort, and reward (Figures 2a-b, S2 and Table S1). Therefore, participants' 
127 choices to help others were affected by the effort and reward levels on offer. In particular,

128 participants were less willing to exert effort to reward other people than themselves.

129 Next we fit and compared a range of different models of effort-discounting to participants

130 choice behaviour using maximum likelihood estimation ${ }^{9,18-20,34}$. These models allowed us to

131 test different theoretical predictions regarding the effect of effort on rewards in the task

132 (whether discounting was linear, hyperbolic, or parabolic) and examine whether people made

133 distinct choices on trials that benefitted themselves or the other person. The winning model in

134 the majority of participants (66\%) was a parabolic model with separate discount parameters

135 ( $K_{\text {self }}$ and $\left.K_{\text {other }}\right)$ and a single noise parameter $(\beta)$, (see Methods, Figure $2 \mathrm{C}-\mathrm{F}$ ). The $2 K$

136 parabolic models outperformed all linear and hyperbolic models, as well as models with only

137 one discount parameter and had the lowest BIC scores. We also further validated our winning

138 model in three ways. First, we calculated the median $\mathrm{R}^{2}$ for the model, and found the model

139 was able to explain $92 \%(S D=10 \%)$ of the variance of choices. Second, we performed model

140 identifiability analyses ${ }^{52}$ using simulated data and showed that our model comparison

141 procedure was robust (see Supplementary Methods and Figure S3). Finally, parameter

142 recovery ${ }^{52,53}$ tested whether the parameters from our best fitting model were recoverable in

143 simulated data based on our schedule. We demonstrated excellent recovery of the 3

144 parameters $\left(K_{\text {self }}=98 \%, K_{\text {self }}, 98 \%, \beta=80 \%\right.$, Figure $\left.2 \mathrm{E}\right)$. We therefore used parameters

145 from the $2 K 1 \beta$ model for all subsequent analyses.

146 We then performed statistical comparison of the estimated $K$ parameters to compare 147 discounting for self and other. This analysis showed that discount values for other were 148 significantly higher for other $\left(K_{\text {other }}\right.$ median $\left.=0.15\right)$ than for self $\left(K_{\text {self }}\right.$ median $=0.07$, Wilcoxon 149 two-sided signed rank test $Z=-5.34$, effect size $r=0.50,[0.30,0.65], p<0.001$, Figure $2 F)$. Thus, 150 the modelling results revealed that as the required effort increases, the subjective value of decisions decreases at a higher rate when making prosocial versus self-benefitting choices. 
A

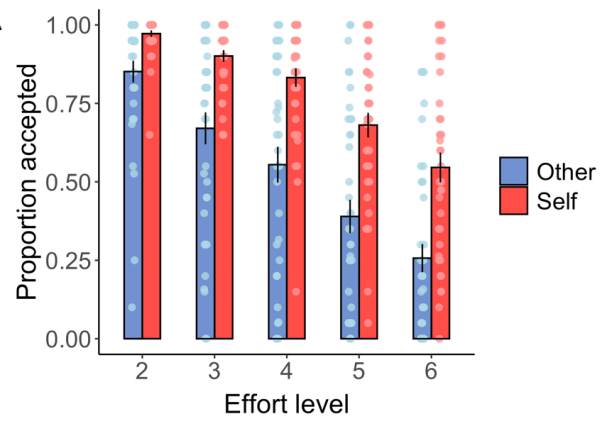

C

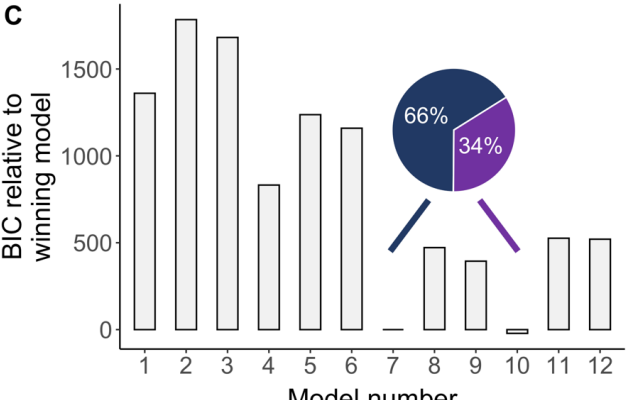

E

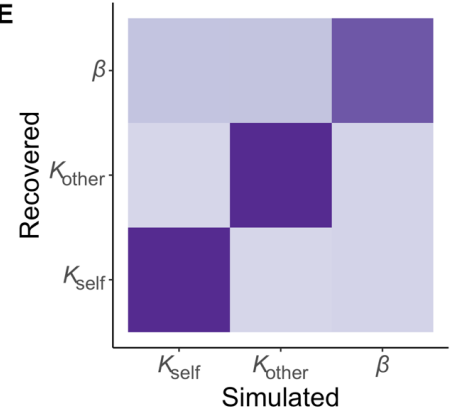

G

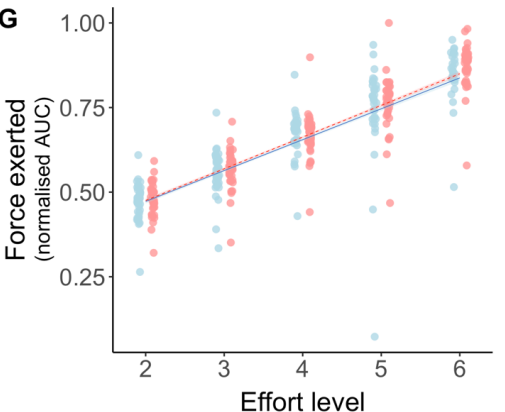

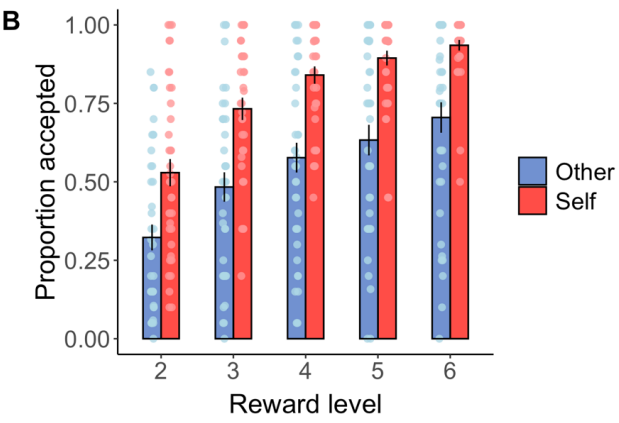

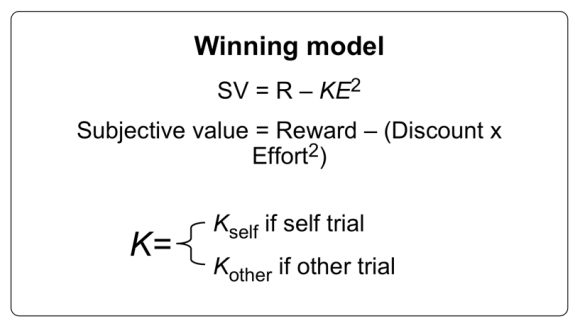

$\mathbf{F}$

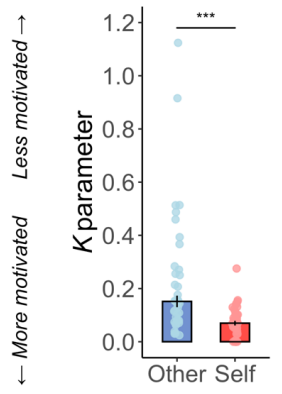

H

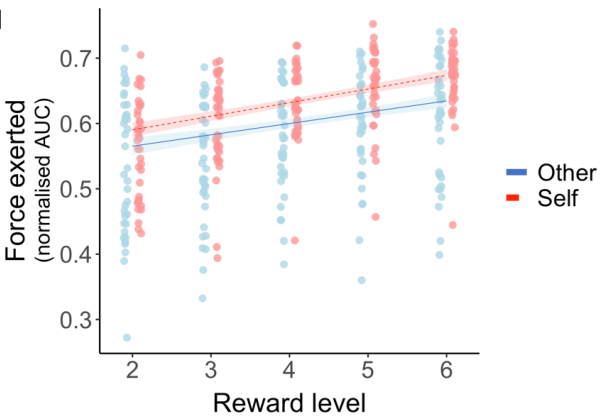

Figure 2. Choice, force, and computational modelling of prosocial and self-benefitting decisions. (A) Participants were less willing to accept the work offer over the rest offer as the effort level increased. (B) The proportion of work offers accepted over the baseline option increased as reward increased. Across effort and reward levels, participants were less willing to work when the other person would benefit than when they would benefit. This tendency to work more for self than others was most pronounced at the higher reward levels and particularly when a high level of effort was required. Data are represented as mean \pm SE. (C) We compared a range of computational models of effort discounting that varied in terms of whether models had a single or separate discount $(K)$ parameter(s) for Self and Other trials (models 1-6 vs. models 7-12) and whether the shape of the discount function was parabolic (models 1, 4, 7,10) linear (models 2, 5, 8,11 ) or hyperbolic (models 3, 6, 9, 12). Models 7 and 10 had the lowest Bayesian Information Criterion $(\mathrm{BIC})$ scores. These were both parabolic and had separate $K$ parameters for self and other. However, model 7 , that contained a single choice stochasticity parameter ( $\beta$ ), explained behaviour in the majority of participants and was selected as the winning model. Bars show model 
bioRxiv preprint doi: https://doi.org/10.1101/2021.09.27.461936; this version posted September 28, 2021. The copyright holder for this preprint (which was not certified by peer review) is the author/funder, who has granted bioRxiv a license to display the preprint in perpetuity. It is made available under aCC-BY 4.0 International license.

167 BIC, proportions show the number of participants with the lowest BIC for model 7 compared to

168 model 10. (D) Equation for the winning parabolic model with separate discount $(K)$ parameters

169 and a single choice stochasticity $(\beta)$ parameter that explained behaviour in the majority of

170 participants. (E) Parameter recovery using simulated data from the winning model and choice schedule showed excellent recovery of the model parameters. (F) Statistical comparison of the $K$ parameters from the best fitting model showed that participants had a lower $K$ parameter for self-benefitting compared to prosocial choices. Data are represented as median $\pm \mathrm{SE}$, ${ }^{* \star *}$ shows $p<0.001$ in Wilcoxon two-sided signed rank test. (G) Force exerted (normalised areas under the curve during the effort period) for each of the levels of effort. Participants exerted less force for others overall and there was a significant 3-way interaction between recipient, effort and reward $(\boldsymbol{p}<.001)$. $(\mathbf{H})$ Force exerted for each reward level shows participants exerted more force

\section{People exert less force when deciding to help others}

A second critical aspect of helping others is that after we have decided to help, we have to energise our actions, and actually exert the effort required, to obtain the prosocial outcome. As well as being less motivated in choosing to put in effort to reward others, people may be less invigorated when helping others and exert less force into prosocial than self-benefitting actions particularly at higher effort levels ${ }^{9,34}$. To test whether people are less invigorated by prosocial acts, we used linear mixed-effects models (LMM) to predict the force that participants exerted on each trial as a function of effort, reward, and their interactions (see Methods). We observed a significant 3-way interaction between effort, reward, and recipient $\left(X^{2}{ }_{(16)}=39.02, p=0.002\right)$. We also found significant interactions between recipient and reward $\left(X^{2}(4)=12.49, p=0.022\right)$, effort and reward $\left(X^{2}(16)=47.78, p=0.001\right)$, and main effects of recipient, effort, and reward (all $\chi^{2} s>24.74$, all $p s<0.001$; Figure $2 \mathrm{G}-\mathrm{H}$ and Table S2). Importantly, there was no significant difference in success between self (mean=0.98) and other trials

192 (mean=0.98, Wilcoxon two-sided signed rank test $Z=-0.59$, effect size $r=0.04$, [0.00,

$1930.26], p=0.55)$ and Bayesian evidence for no difference $\left(\mathrm{BF}_{01}=4.35\right.$, substantial evidence in 194 support of the null). Therefore, consistent with previous studies, participants applied less force

195 for other benefitting than self-benefitting decisions, particularly at high effort levels, but were not less successful ${ }^{9,34}$.

\section{Prosocial and self-benefitting neural computations}

198 To test whether there were distinct or common neural processes when making decisions to 199 benefit self or other, we first took a multivariate, Representational Similarity Analysis (RSA)

200 approach $^{51,54}$. RSA can complement and add to inferences that are made based upon

201 univariate $\mathrm{fMRI}$ analyses. The approach has similarities to population analyses often applied

202 to neurophysiological recordings. As such, it can be used to link together the algorithmic and

203 implementational levels of interpretation of $\mathrm{fMRI}$ data ${ }^{12,55}$. RSA is well suited to designs 
bioRxiv preprint doi: https://doi.org/10.1101/2021.09.27.461936; this version posted September 28, 2021. The copyright holder for this preprint (which was not certified by peer review) is the author/funder, who has granted bioRxiv a license to display the preprint in perpetuity. It is made available under aCC-BY 4.0 International license.

204 where stimuli can be processed along continuums in different dimensions, but also linked to

205 one another via different ways ${ }^{56}$. As such, it was ideal for this experiment where the work

206 offers can be parametrised in terms of effort level, reward level or combined to calculate the

207 subjective value. This technique allowed us to examine whether patterns of responses

208 across voxels were more or less dissimilar as a function of each of these three decision

209 variables. Thus, we used RSA to uniquely address questions about neural representations

210 of information that guide decision-making for oneself and others ${ }^{51,57}$.

211

212 We calculated brain RDMs coding for dissimilarity (correlation distance ${ }^{57}$ ) in multivariate

213 patterns of voxels for all pairs of experimental conditions. Since the task comprised of 5

214 levels of effort and 5 levels reward for each recipient this resulted in a $25 \times 25$ matrix that

215 was computed separately for self and other trials (Figure 1A-B, see Methods and

216 Supplementary Methods for full details of RSA analyses). To evaluate whether these

217 multivariate brain patterns reflected hypothesised processes, we created six behavioural

218 model RDMs which reflected the dissimilarity in self-effort, other-effort, self-subjective value

219 and other-subjective value (from the winning computational model), and self-reward, other-

220 reward. Inferences were drawn by correlating each model RDM with each brain RDM using

221 Kendall's $\tau_{A}{ }^{54}$. Brain RDMs were calculated using both a hypothesis driven, anatomically

222 specific region of interest (ROI) approach (see below) and a whole-brain data-driven

223 searchlight approach (see Methods).

224 In addition to the multivariate approach, we also conducted two univariate analyses. The first

225 used the trial-by-trial subjective values from the best-fitting computational model at the time of

226 choice, to compare whether our ROIs also carried univariate signals of subjective value. The

227 second univariate analysis was applied to examine activity time-locked to the force period,

228 which scaled with the amount of effort required (Figure 1A), to examine whether any brain

229 areas distinguished between energising actions which benefit self or other. Due to the

230 variability between participants in the number of repetitions of effort levels - which depended

231 on participant choice behaviour - a multivariate analysis was not suitable (since the difference

232 in number of repetitions could impose structure on the RDMs). We created a GLM including

233 regressors time-locked to the offer cue, and to the force period, separately for self and other

234 trials. We included parametric modulators of the required effort level time-locked to the force

235 period, and subjective value from the winning computational model time-locked to the offer 236 cue. 
bioRxiv preprint doi: https://doi.org/10.1101/2021.09.27.461936; this version posted September 28, 2021. The copyright holder for this preprint (which was not certified by peer review) is the author/funder, who has granted bioRxiv a license to display the preprint in perpetuity. It is made available under aCC-BY 4.0 International license.

237 The aim of this study was to test specific hypotheses about regions that have previously been

238 linked to guiding effort-based decisions and those linked to processing social information that 239 could guide prosocial behaviours. Given extensive previous work on the neural systems 240 involved in social decision-making ${ }^{12,35,58}$ and self-relevant effort-based decision-making ${ }^{18,24-31}$ 241 we focused our fMRI analysis on four ROls where we had strong a priori hypotheses using 242 independent anatomical masks defined using pre-existing parcellations (see below). These 243 masks also allowed us to probe distinct contributions of different portions of the cingulate 244 cortex, distinguishing dorsal dACC/dmPFC (area $8 \mathrm{~m}$ ) $18,24,28$ from more ventral portions of the 245 ACC gyrus (ACCg) 12,35,36,58 (Figure S4, see Methods). We also included ROIs of the anterior 246 insula $(\mathrm{Al})^{59}$ and temporo-parietal junction (TPJ) ${ }^{60}$. In addition to these four ROls, we conducted exploratory whole-brain analyses for completeness and considered areas significant that survived correction for multiple comparisons at the cluster level $(p<.05$, corrected for family-wise error (FWE) after thresholding at $\left.p<.001^{61}\right)$, both in the data-driven searchlight and in the univariate analyses.

\section{Patterns of prosocial effort in $\mathrm{ACCg}$}

252 To test the hypothesis that there are regions that distinctly code prosocial efforts we compared 253 multivariate patterns between self and other trials separately (Figure 1). For a region to be 254 considered as coding prosocial, and not self-benefitting, effort, its RDM should correlate with 255 the other-effort model RDM, and not with the self-effort model RDM, and there should be a 256 significant difference between the strength of those correlations. Such a correlation would 257 demonstrate that the neural patterns discriminate strongly between task conditions that vary 258 in the levels of effort that are required to be put in for another person; but the same patterns 259 do not vary with the differences in effort level when the decisions are about oneself. In line 260 with our hypothesis, the ACCg ROI carried a multivariate representation of effort on prosocial 261 trials (other-effort mean rank correlation $\tau_{A} \pm S E$ : $A C C g=0.026 \pm 0.009, p=0.005$, surviving 262 FDR correction for 24 comparisons (6 models, 4 brain areas, 2 recipients), and was the only 263 ROI to display a significant difference between the other-effort and self-effort RDMs (Wilcoxon 264 two-sided signed rank test $Z=-2.73$, effect size $r=0.44,[0.13,0.69], p=0.006$, Figure $3 A$ ).

265 Multivariate patterns in our three other ROls also showed significant correlations with the other-effort RDM when making prosocial choices (other-effort mean rank correlation $\tau_{A} \pm S E$ : $\mathrm{TPJ}=0.033 \pm 0.010, p=0.001 ; \mathrm{Al}=0.021 \pm 0.008, p=0.006 ; \mathrm{dACC} / \mathrm{dmPFC}=0.029 \pm$ $0.008, p=0.001)$. In contrast for self-effort patterns, only the TPJ brain RDM significantly correlated with the self-effort model RDM (self-effort mean rank correlation $\tau_{A} \pm S E: A C C g=$ 
$0.002 \pm 0.009, p=0.61 ; \mathrm{TPJ}=0.024 \pm 0.010, p=0.026 ; \mathrm{Al}=0.008 \pm 0.009, p=0.40$ $\mathrm{dACC} / \mathrm{dmPFC}=0.016 \pm 0.010, p=0.16)$. Critically, although TPJ, Al and dACC/dmPFC also represented prosocial effort, they did not do so more strongly than for the self-effort RDMs (Wilcoxon two-sided signed rank test, all ps>0.07).

274 Notably the specificity for others effort in the ACCg was not due to total differences for other and self representations, as the ACCg represented other and self offers as equally dissimilar (see Methods, Bayesian paired sample t-test $\mathrm{BF}_{01}=4.61$, substantial evidence in support of the null). Moreover, whilst patterns in several regions significantly correlated with the otherreward RDM (other-reward mean rank correlation $\mathrm{T}_{\mathrm{A}} \pm \mathrm{SE}$ : $\mathrm{ACCg}=0.009 \pm 0.007, p=0.16$; $\mathrm{TPJ}=0.016 \pm 0.007, p=0.027 ; \mathrm{Al}=0.020 \pm 0.008, p=0.006 ; \mathrm{dACC} / \mathrm{dmPFC}=0.025 \pm$

$2800.007, p=0.001$ ), no region significantly represented others' rewards more strongly than selfrewards (Table S3). Thus, multivariate patterns in the ACCg represented effort costs specifically when making prosocial but not self-benefitting choices (see Table S4 for exploratory whole-brain searchlight results).

\section{Parametric modulation of effort level when exerting force for others in $\mathbf{A C C g}$}

We next used univariate analysis to determine regions in which activity scaled with required effort level during the force period. We found that the BOLD response in ACCg positively covaried with force for others $(x=4, y=2, z=36, z=k=455, p=.001$, FWE-corrected), and an overlapping cluster also showed a significant effect coding force for other $>$ than self $(x=-6$, $y=24, z=20, z=3.28, k=41, p<.05$, FWE-SVC, Figure 3B). Analysis of the force period also showed at the whole-brain level that the left TPJ positively tracked force exerted for others more than self ( $x=-50 y=-62 z=40, Z=4.85, k=790, p<.001$ FWE-whole brain), with activation for other greater than self on the right side evident at small-volume corrected levels $(x=52, y=-$ $56, z=40, Z=3.65, k=29, p<.05 \mathrm{FWE}-S V C)$. A region in the bilateral middle insula ( $x=-38 \mathrm{y}=0$ $z=12, Z=3.96, k=105, p<.05$, FWE-SVC; $x=44 y=4 z=10, Z=3.65, k=83, p<.05$, FWE-SVC) tracked both self and other force exerted, but responded more strongly to other. Outside of our ROls, we also observed significant tracking of force exerted for other more than self in a region of the superior frontal gyrus extending into the paracingulate cortex and middle temporal gyrus (Supplementary Table S5). No brain areas significantly responded more to the contrast self force>other force at the whole brain level or in any of our ROIs.

300 Therefore, whilst several regions processed information about prosocial efforts, only the ACCg 301 showed a more specialised profile. Multivariate patterns in the ACCg specifically encoded 
bioRxiv preprint doi: https://doi.org/10.1101/2021.09.27.461936; this version posted September 28, 2021. The copyright holder for this preprint (which was not certified by peer review) is the author/funder, who has granted bioRxiv a license to display the preprint in perpetuity. It is made available under aCC-BY 4.0 International license.

302

303

304

305

representations of prosocial effort when making a choice, and univariate signals in this region scaled with how much effort was required when energising prosocial acts, with no such signals for self-benefitting efforts.

A

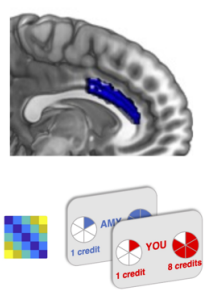

Other effort pattern > Self effort pattern

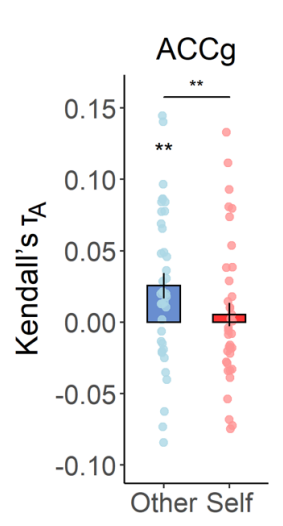

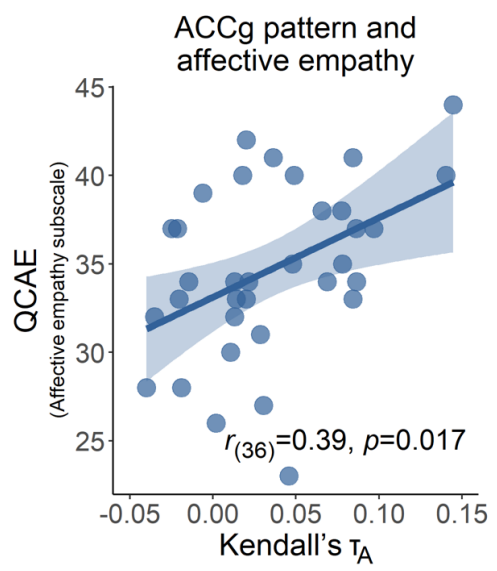

B Other force $>$ Self force
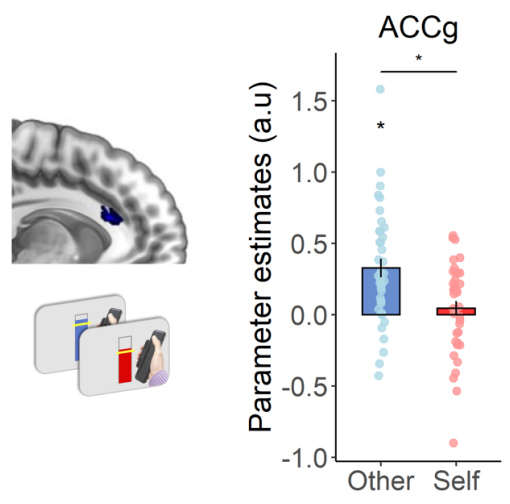

306

307

308

309

310

311

312

313

314

315

316

317

318

319

320

321

322

323

324

325

326

327

328

329

330

331

Figure 3. ACCg codes patterns of effort for others only, varies with level of affective empathy, and tracks effort required to benefit others only. (A) Across an independent structural ROI of the anterior cingulate gyrus (Neubert et al., 2014), multivoxel patterns of effort were encoded specifically for others. Kendall's $\tau_{A}$ indicates the extent to which the effort model RDM explains pattern dissimilarity between voxels in ACCg. ACCg shows a significant correlation between the effort model RDM and the brain RDM for other (mean rank correlation $\left.\tau_{A} \pm S E: A C C g=0.026 \pm 0.009, p=0.005\right)$, as well as a greater correlation between the brain RDM and effort RDM for other compared to self (Wilcoxon two-sided signed rank test $Z=-$ 2.73 , effect size $r=0.44,[0.13,0.69], p=0.006$. ROI displayed on an anatomical scan of the medial surface. Variability in ACCg effort patterns for others was explained by individual difference in affective empathy, as measured by the Questionnaire for Cognitive and Affective

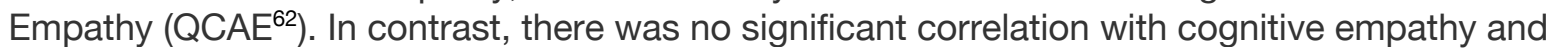
the two corelations were significantly different from one another ( $t=2.04, p=0.024)$. (B) A univariate analysis time-locked to the onset of the force period showed a cluster in the ACCg that tracked the amount of effort required during the force period specifically when making prosocial but not self-benefitting decisions ( $x=-6, y=24, z=20, z=3.28, k=41, p<0.05$, FWE-SVC). Activation overlaid on an anatomical scan of the medial surface. ${ }^{*} p<0.05,{ }^{* *} p<0.01{ }^{* \star *} p<0.001$.

\section{Multivariate representations of prosocial effort in $\mathrm{ACCg}$ correlate with individual} differences in affective empathy

Theoretical accounts suggest that empathy plays a key role in motivating prosocial behaviours ${ }^{36,63,64}$ with self-reported empathy a predictor of people's willingness to exert effort to obtain rewards for others and also with responses in the ACCg when processing social information $33,36,40,65$. Thus we next sought to evaluate whether multivariate and univariate signals of prosocial effort varied with individual differences in empathy. Since we found evidence for specific effort patterns during prosocial acts in ACCg only, we focused our analysis on responses in this region. We found that affective empathy was positively 
332 correlated with the strength of correlation between the brain RDM patterns in ACCg and the

333 other-effort RDM (Pearson's $r_{(38)}=0.39, p=0.017$, Figure $3 \mathrm{~A}$, right) whilst cognitive empathy

334 was not (Pearson's $r_{(38)}=0.05, p=0.78$, correlations significantly different $t=2.04, p=0.02$ ). For

335 the tracking of prosocial effort in ACCg during force exerted, neither affective or cognitive

336 empathy were significantly correlated (all $r s>-0.18$, all $p s>0.29$ ). Thus, individuals who

337 reported being more affectively empathic represented the effort of behaviours more distinctly

338 in the ACCg when deciding whether to act prosocially.

\section{Specific coding for self-benefitting acts in midbrain and Al}

340 Do any regions specifically code self-benefitting acts when making effort-based decisions?

341 None of our ROls showed a stronger correlation of the self-effort than other-effort RDM, and

342 similarly for the SV RDM, no region showed a significantly stronger correlation for self than

343 other (all $Z s<1.37 \|>1.56$, all ps $>0.12$, see Table S3 for reward RDM results). However, a

344 whole-brain exploratory searchlight analysis revealed a significantly stronger correlation with

345 the self-SV than other-SV model RDM in the midbrain, putatively in the ventral tegmental area

346 (VTA; $x=4, y=-22, z=16, k=291, Z=4.45, p=.033$ FWE-whole brain corrected, Figure 4A, Table

$347 \mathrm{~S} 4)$ and in the posterior cingulate $(x=20, y=-20, z=50, Z=4.78, k=578, p=.002$, FWE-whole

348 brain corrected, Table S4). The univariate analysis revealed a cluster in a ventral portion of

349 the left anterior insula ( $\mathrm{VAl}$; $\mathrm{x}=-44 \mathrm{y}=10 \mathrm{z}=-10, \mathrm{Z}=3.72, \mathrm{k}=59, p<0.05 \mathrm{FWE}$-small volume) in

350 which activity scaled more strongly with SV when making self-benefitting than other benefitting

351 choices (Figure 4B). This cluster did not overlap with one that signalled SV on both self and

352 other trials (see Supplementary Figure S4C). Such findings suggest that the VTA is engaged

353 exclusively in making choices about whether it is worth exerting effort to benefit oneself, and

354 vAl tracks subjective value more closely during self-benefitting than other-benefitting 355 decisions. 


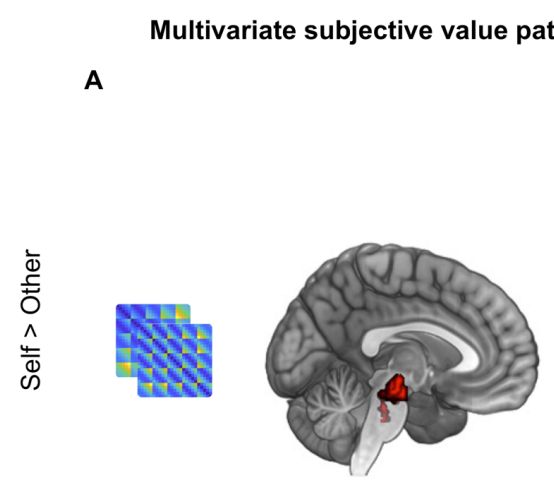

C

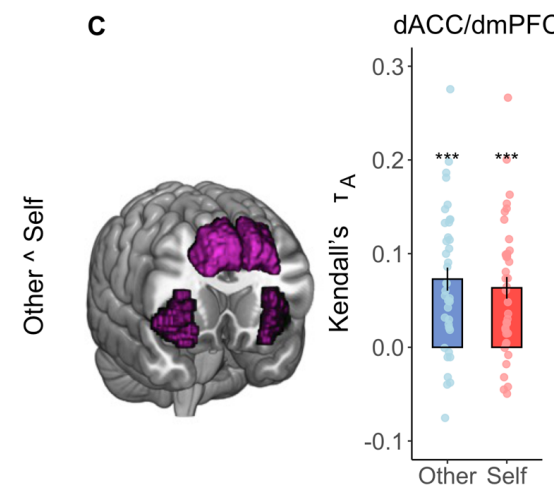

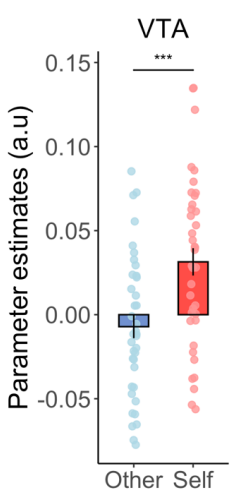

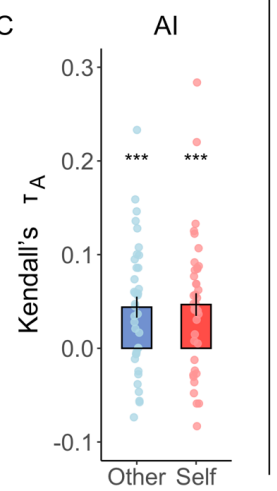

Univariate subjective value tracking

B
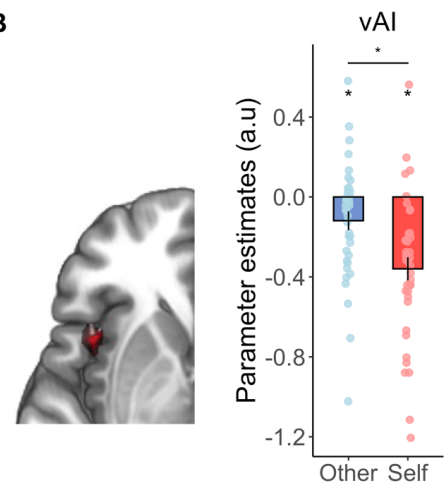

D

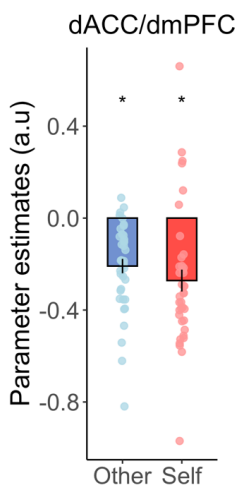

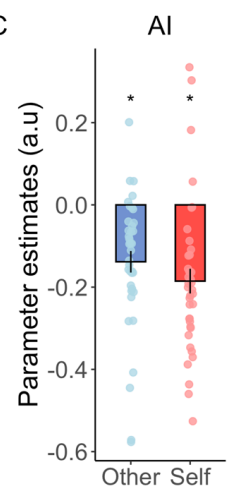

Figure 4. Self-benefitting and domain general representations and tracking of subjective value. (A) A cluster putatively in the ventral tegmental area (VTA) encoded representational patterns of subjective value exclusively on self-benefitting trials $(x=4, y=-22, z=16, k=291$, $\mathrm{Z}=4.45, p=0.033 \mathrm{FWE}$-whole brain corrected after thresholding at $p<0.001$ ). (B) A sub-region of the ventral anterior insula (vAl; $x=-44 y=10 z=-10, Z=3.72, k=59, p<0.05$ FWE-small volume) tracked subjective value of the chosen offer trial-by-trial more strongly for self-benefitting than other-benefitting choices. (C) The dACC/dmPFC and Al showed significant correlations between the brain RDM and subjective value RDM pattern for both other and self offers, consistent with a domain general response in these regions. (D) Univariate analysis also showed trial-by-trial tracking of subjective value in dACC/dmPFC ( $x=8 \mathrm{y}=26 \mathrm{z}=34, \mathrm{Z}=4.75$, $\mathrm{k}=1033, p<0.05$ FWE-whole brain) and Al (left: $\mathrm{x}=-28 \mathrm{y}=22 \mathrm{z}=6, \mathrm{Z}=4.47, \mathrm{k}=306, p<0.001 \mathrm{FWE}-$ SVC; right: $\mathrm{x}=34, \mathrm{y}=24, \mathrm{z}=2, \mathrm{Z}=4.38, \mathrm{k}=222, p<0.05$ FWE-small volume) for both self and other. ${ }^{*} p<0.05,{ }^{* *} p<0.01{ }^{* \star *} p<0.001$.

370 Domain-general multivariate and univariate signals of subjective value for self and other.

Previous research using univariate approaches has repeatedly implicated the $d A C C / d m P F C$ and $\mathrm{Al}$ in signalling SV during self-benefitting, effort-based choices in a domain-general manner regardless of the nature of the cost ${ }^{18,24,28}$. Next, we tested whether these regions contain information about SV when making both self-benefitting and prosocial choices (see Methods). We found significant correlations between the self-SV and other-SV RDMs in both the $\mathrm{dACC} / \mathrm{dmPFC}$ and $\mathrm{Al}$ (self-SV mean rank correlation $\tau_{\mathrm{A}} \pm \mathrm{SE}$ : $\mathrm{dACC} / \mathrm{dmPFC}=0.063 \pm$ 
$0.012, p<0.001 ; \mathrm{Al}=0.047 \pm 0.012, p<0.001$; other-SV mean rank correlation $\tau_{\mathrm{A}} \pm \mathrm{SE}$ : $\mathrm{dACC} / \mathrm{dmPFC}=0.073 \pm 0.012, p<0.001 ; \mathrm{Al}=0.051 \pm 0.013, p<0.001 ;$ all survive FDR correction, Figure 4C). Moreover, univariate conjunction analysis of trial-by-trial subjective value also revealed activity covarying with $S V$ on both self and other trials in dACC/dmPFC ( $x=8$ y=26 z=34, Z=4.75, k=1033, $p<.05$ FWE-whole brain, Figure 4D) and bilateral Al (left: $x=$ $-28 \mathrm{y}=22 \mathrm{z}=6, \mathrm{Z}=4.47, \mathrm{k}=306, p<.001$ FWE-SVC; right: $\mathrm{x}=34, \mathrm{y}=24, \mathrm{z}=2, \mathrm{Z}=4.38, \mathrm{k}=222$, $p<.05$ FWE-SVC, Figure 4D) that overlapped with the same portions of $\mathrm{dACC} / \mathrm{dmPFC}$ and $\mathrm{Al}$ that coded the multivariate pattern. Importantly neural responses to subjective value in $\mathrm{dACC} / \mathrm{dmPFC}$ and $\mathrm{Al}$ were evident both from multivariate and univariate analyses. This is striking given that the correlation distance is invariant to the mean activation level across voxels ${ }^{51,66}$, rendering the multivariate and univariate predictions of neural response separate (see Methods).

Outside of $\mathrm{dACC} / \mathrm{dmPFC}$ and $\mathrm{Al}$, we found multivariate patterns of subjective value that overlapped between self and other in TPJ and ACCg (self-SV mean rank correlation $\tau_{A} \pm S E$ : TPJ $=0.026 \pm 0.011, p=0.018 ; \mathrm{ACCg}=0.055 \pm 0.012, p<0.001$; other-SV mean rank correlation $\tau_{\mathrm{A}} \pm \mathrm{SE}$ : TPJ $=0.044 \pm 0.011, p<0.001 ; \mathrm{ACCg}=0.038 \pm 0.014, p=0.009$; all survive FDR correction). At the whole-brain level, searchlight analysis also showed responses in the superior frontal gyrus, inferior parietal lobe and precentral gyrus in conjunction analyses (Table S4). No other areas significantly tracked self and other SV in any of our ROls or at the whole-brain level. For effort, domain general patterns were observed in the bilateral precuneus (Table S4) and for reward, in bilateral precentral gyrus, cuneus, and paracentral lobule (Table S4). Univariate conjunction analysis of effort required during the force period demonstrated wide-ranging activation at the whole-brain level, centring on the precentral gyrus and cerebellum (Table S4).

\section{Discussion}

Many prosocial acts are effortful. However, the neural mechanisms that underlie how people decide whether to exert effort into prosocial acts, and whether such mechanisms are distinct from self-benefitting acts, are poorly understood6. Here, we show that the ACCg processes information that is crucial for making effort-based decisions when they are prosocial, but not when they are self-benefitting. The ACCg carried a multivariate representation of effort when deciding whether to help others, and showed a univariate response to the degree of effort required whilst energising prosocial acts. The representation of effort in this area was also stronger in individuals higher in self-reported empathy. In addition, we found a region in the 
bioRxiv preprint doi: https://doi.org/10.1101/2021.09.27.461936; this version posted September 28, 2021. The copyright holder for this preprint (which was not certified by peer review) is the author/funder, who has granted bioRxiv a license to display the preprint in perpetuity. It is made available under aCC-BY 4.0 International license.

411 midbrain which processed information only when making self-benefitting effort-based choices,

412 a portion of the ventral Al that tracked self subjective value more closely than other subjective 413 value, as well as domain-general representations of SV in the dACC/dmPFC and distinct 414 portions of bilateral Al. These findings highlight the importance of effort for understanding the 415 neural mechanisms of prosocial behaviour, and that multivariate patterns and univariate 416 model-based signals differentiate between prosocial and self-benefitting effortful acts.

417 There is a growing body of evidence to suggest that the ACCg is a vital cingulate sub-region 418 for social cognition, and particularly for vicariously processing information about others ${ }^{35,36}$. In 419 macaques, lesions to this region, but not neighbouring sub-regions, reduce sensitivity to social 420 stimuli67. Neurophysiological recordings indicate that the ACCg contains a higher proportion 421 of neurons that respond exclusively when seeing others obtain a reward, but not when getting rewarded oneself 37 . In rodents, a putatively homologous region contains neurons that respond when seeing another receiving electrical shocks and when exerting competitive efforts ${ }^{68-70}$. In

424 humans, single-unit recordings have identified that ACCg contains neurons that signal at the time of outcomes being delivered when learning from others', but not one's own reward, prediction errors ${ }^{71}$. In addition, neuroimaging studies have shown that this region responds to cues that are predictive of rewarding outcomes for others and not self, signals the value of others' rewarding outcomes but not one's own when they will have to exert effort for them, and encodes social prediction errors at the time of the outcomes of others actions ${ }^{35,36,41}$.

430 Combined this work suggests that the ACCg processes information about others that it does 431 not process about ourselves. However, despite this work highlighting a role in vicariously 432 processing others' outcomes, whether and how this related to behaviours aimed at benefitting others, or prosocial efforts was unclear.

434 Crucially, we found other-specific effort effects in the ACCg that went beyond vicarious 435 processing of others' outcomes, and extended them to prosocial behaviours. Such findings 436 suggest that vicarious signals in the ACCg may not be epiphenomenal or simply reflecting 437 one's emotional responses to others outcomes, but instead they drive behaviour ${ }^{11,12}$. In 438 particular, the ACCg may be crucial for motivating people to help others, and overcome 439 barriers to others receiving positive outcomes. Consistent with this, we found representations 440 of effort in the ACCg both when making prosocial decisions, and when energising prosocial 441 but not self-benefitting actions. Our finding fits with the notion that ACCg patterns do not simply 442 reflect the reduced willingness to put in effort for others at higher effort levels, since similar 443 self-benefitting effort representations were absent in $\mathrm{ACCg}$, and those higher in empathy 444 represented the distinction between effort costs more strongly, not less. Interpreting ACCg 
bioRxiv preprint doi: https://doi.org/10.1101/2021.09.27.461936; this version posted September 28, 2021. The copyright holder for this preprint (which was not certified by peer review) is the author/funder, who has granted bioRxiv a license to display the preprint in perpetuity. It is made available under aCC-BY 4.0 International license.

signals as being important for motivating actions that benefit others, rather than inhibiting them, may explain why lesions to the ACCg impair the effortful process of learning of new prosocial action-outcome associations, but not the execution of low effort previously learned prosocial acts ${ }^{72,73}$. Moreover, our results suggest that the finding of functional connectivity in local field potentials between the amygdala and ACCg when monkeys allocate rewards to others ${ }^{74}$, may be linked to ensuring the monkeys overcome any costs associated with being prosocial. Together our results indicate that the ACCg is involved in motivating the overcoming of effort costs to be prosocial, rather than being involved in effort-discounting per se.

The notion that prosocial acts can be considered as goal-directed acts, governed by similar principles and computational mechanisms as non-goal-directed actions, but implemented in distinct neural regions, highlights the need to examine effort processing to understand what makes people help others ${ }^{6}$. Recently, it has been shown that higher levels of affective empathy are linked to a greater willingness to exert effort to benefit others ${ }^{33,65}$. Here, we show that such individual variability may be linked to ACCg prosocial effort processing, with levels of affective empathy correlated with the strength of multivariate representations of prosocial effort costs when deciding whether to help others. Although the link between empathy and prosocial behaviour is often discussed, many of the mechanisms providing this link are poorly understood $36,65,75$. Our findings demonstrate that representing how costly and effortful a prosocial behaviour is, may be linked to how strongly one represents the emotional states of others, which leads to variability in how willing people are to help others.

Although we found that some regions processed information differently when making decisions about whether to exert effort to benefit self or other, several regions - and particularly the $\mathrm{Al}$ and $\mathrm{dACC} / \mathrm{dmPFC}$ - encoded information regardless of the beneficiary. Whilst there has been some debate surrounding whether these regions encode SV in univariate $\mathrm{fMRI}$ studies of effort-based decision-making ${ }^{18,26,30,31,76-78}$, a large body of evidence suggests that lesions to these regions reduces levels of motivation ${ }^{24,32}$. Neurons in the dACC signal both reward value and effort costs ${ }^{79}$. In addition, a recent meta-analysis of fMRI studies highlights consistent evidence that these regions signal the SV during effort-based decisionmaking ${ }^{28}$. It has been argued that responses in these areas may be domain-general, with SV encoded regardless of the nature of the effort, whether it is physical or cognitive ${ }^{18,28}$. Our results extend this notion, as previous work has exclusively used univariate approaches. We show multivariate representations of SV are present in these same regions regardless of whom the effort is being exerted for. Such a finding supports the idea that neural processes 
bioRxiv preprint doi: https://doi.org/10.1101/2021.09.27.461936; this version posted September 28, 2021. The copyright holder for this preprint (which was not certified by peer review) is the author/funder, who has granted bioRxiv a license to display the preprint in perpetuity. It is made available under aCC-BY 4.0 International license.

domains, regardless of the nature of the effort or who will receive the reward. Importantly, this also suggests that decisions to behave prosocially are distributed across both regions specialised for prosocial behaviour and those similarly involved in effort-based decisions in non-social contexts.

Notably we also found a midbrain region, closely approximating the VTA, that contained a multivariate representation of SV exclusively when making choices to benefit oneself. Previous work across species has linked the VTA to exerting effort for one's own rewards ${ }^{76,80-}$ 83. Neurophysiological recordings in this region highlight that local field potentials are sensitive to effort requirements and that neurons in this region increase prior to deciding whether to exert effort ${ }^{10,80}$. Neuroimaging studies in humans suggest the VTA may be important for learning how to avoid effort costs and when deciding how much effort to allocate to a trial of a task $^{76,82,83}$. However, our results suggest that this region may not process information for all efforts, only for those that benefit oneself. Such findings concord with the idea that prosocial and self-benefitting actions are distinct, may be linked to partially distinct motivational processes, and argue against some suggestions that a 'warm glow' is the primary driver of prosocial acts $8,33,34,65,75$. The warm glow account would suggest that the same mechanisms are engaged when thinking about the benefits of helping others and when benefitting oneself. Instead, we show that choosing whether to benefit ourselves may recruit some systems that are not deployed when making similar prosocial choices. This supports the idea that how prosocial one is, and one's levels of social motivation, may be independent of how motivated one is to exert effort to benefit ourselves.

Recently we highlighted how using the framework of Marr's three levels, can be fruitful for examining if a process is socially, or self, specific, either in how it is implemented in the brain, or in its algorithmic processes ${ }^{12}$. In line with this approach, our findings highlight the critical importance of breaking prosocial behaviour down into its constituent parts, for using multivariate approaches, and for designing paradigms that separate out self-benefitting from other-benefitting decision-making. Previous work examining prosocial behaviour, particularly that using economic games, has been crucial for implicating the systems that involved1,84-86.

507 However, the precise computations performed have been hard to identify due to the challenge 508 of untangling self-benefitting from other-benefitting components. We reveal that several 509 regions, including in the $\mathrm{Al}$ and $\mathrm{dACC} / \mathrm{dmPFC}$ which have been implicated in prosocial 510 behaviours ${ }^{48}$, in fact carry information when making both self-benefitting and other-benefitting 511 choices. Such a finding raises the possibility that these areas may be less directly linked to 512 prosocial behaviour, and more linked to domain-general decision processes during economic 
bioRxiv preprint doi: https://doi.org/10.1101/2021.09.27.461936; this version posted September 28, 2021. The copyright holder for this preprint (which was not certified by peer review) is the author/funder, who has granted bioRxiv a license to display the preprint in perpetuity. It is made available under aCC-BY 4.0 International license.

513 games. Moreover, by measuring both self and other decision-making, we were able to identify 514 an at least partially self-specific processes in the VTA and a different sub-region of AI, and 515 prosocially specific representation of effort in the ACCg.

516 In conclusion, many prosocial acts require effort. Using computational modelling of behaviour, 517 and multivariate and univariate analyses of $\mathrm{FMRI}$ data, we find evidence of distinct neural 518 patterns of effort for prosocial and self-benefitting acts. The ACCg carries a multivariate 519 representation of effort when making prosocial choices, and is engaged when energising 520 prosocial acts, but does not carry similar information for self-benefitting choices or acts. In 521 addition, we show that the Al and dACC/dmPFC all carry information that guides both self522 benefitting and prosocial behaviours. Intriguingly, these areas both represent the dissimilarity 523 between different subjective values within a neural pattern, as well as tracking the quantity of 524 subjective value trial-by-trial. In contrast, the VTA processes the structure of subjective value 525 only of self-benefitting acts and the ventral Al more closely tracks self-benefitting, compared 526 to other-benefitting, values. These findings provide a unique insight into how the brain makes 527 decisions about whether to put in effort to help others out.

\section{Materials and Methods}

\section{Participants}

53041 healthy, right-handed participants took part. Three participants were excluded. Two who 531 did not believe the deception in the study set-up (see "Role assignment" details below), and 532 one who never chose to exert effort for the other person. The final group of 38 participants (26 533 females, mean age 23, range 18-34). Based on the effect size from Lockwood et al., ${ }^{9}$ a sample 534 of 38 people gave $83 \%$ power to detect a significant behavioural effect.

535 Participants were recruited through student mailing lists, online advertisements on a study 536 recruitment board, through social media, and by word of mouth. The study was described as 537 a social decision-making study involving pairs of participants. Participants believed that, on 538 the day of testing, one of the pair would be randomly allocated to complete the task in the 539 fMRI scanner whilst the other would complete the task in a testing room. In reality, all 540 participants completed the task in the scanner, and a confederate served as the other 541 participant. Exclusion criteria were previous study of psychology, previous participation in a 542 study involving social interactions, left handedness, and neurological or psychiatric disorder.

543 These questions were asked via an online screening procedure and only participants who met 544 these criteria were invited to take part. The study was approved by the Medical Sciences 
bioRxiv preprint doi: https://doi.org/10.1101/2021.09.27.461936; this version posted September 28, 2021. The copyright holder for this preprint (which was not certified by peer review) is the author/funder, who has granted bioRxiv a license to display the preprint in perpetuity. It is made available under aCC-BY 4.0 International license.

545 Division Research Ethics Committee of the University of Oxford. Participants were paid for 546 their participation at a rate of $£ 15 / h o u r$, plus a bonus of up to $£ 5$ based on the credits they 547 earned in the task. They were also told the number of credits that they earned in the prosocial 548 condition would translate into an additional payment of up to $£ 5$ for the other participant (see 549 details of the task below).

\section{Procedure}

551 Approximately 1 week before attending the testing session, participants completed a 552 questionnaire assessment of empathy online using the Questionnaire of Cognitive and 553 Affective Empathy (see below for further details). Participants then attended the lab to 554 complete a physical effort-based decision-making task modified for scanning from previous 555 behavioural studies ${ }^{9,34}$. Physical effort was operationalized as the amount of force participants 556 exerted on a handheld dynamometer. On arrival and after consent, participants were 557 instructed to squeeze the handheld dynamometer as hard as they could. Participants were 558 provided with visual feedback whilst doing so and encouraged to reach a line that was $110 \%$ 559 of their maximum voluntary contraction (MVC) which they repeated for 3 trials. After this 560 thresholding procedure, and before any task instructions, participants were introduced to 561 another participant anonymously (see "role assignment' procedure below). Participants 562 practiced each of the 5 effort levels twice to ensure that they could be achieved. In the main 563 task inside the fMRI scanner, participants were prompted to choose between one of two offers 564 on each trial. One option allowed participants to earn a low reward for low effort (rest); the 565 other presented a variable higher-reward, higher-effort offer (work) of the same duration. The 566 low-reward, low-effort offer earned 1 point and required no effort. Higher-reward, higher-effort 567 offers varied from 2-10 points (in 2-point increments). Effort ranged from $30-70 \%$ (in $10 \%$ 568 increments) of the participants' MVC. Participants were aware that points earned 569 corresponded to later compensation, but were not made aware of the exchange rate while 570 completing the task. Critically, each trial also varied in whether the outcome would be delivered 571 the participant themselves (Self) or the receiver participant (Other, prosocial). The level of 572 effort required for each offer was represented using coloured portions of a pie chart (Figure 573 1). Rewards (points) on offer for each option were written in colour below. Participants were 574 allotted 3.5 seconds to make a choice between the rest and work offers. If they failed to choose 575 an option, they were awarded 0 points after a full trial duration. After choosing, participants 576 were shown a screen with a yellow horizontal bar on an empty vertical box. The horizontal bar 577 represented the level of effort required; the box filled according to the force participants 578 exerted on the dynamometer, providing feedback in real-time. For a trial to be considered 
bioRxiv preprint doi: https://doi.org/10.1101/2021.09.27.461936; this version posted September 28, 2021. The copyright holder for this preprint (which was not certified by peer review) is the author/funder, who has granted bioRxiv a license to display the preprint in perpetuity. It is made available under aCC-BY 4.0 International license.

successful, and rewards obtained, participants had to accumulate at least 1 second at or above the required force level across the 3 second force period.

581 The task was broken into four blocks, with a minute break in between each block to rest and prevent the build-up of fatigue. Participants selected the choice they wanted using a game controller in their left hand and used their right hand to squeeze the dynamometer. Each participant completed 100 interleaved trials per recipient (self or other).

\section{Role assignment.}

586 Participants were introduced to another participant who was in fact a confederate of the 587 experimenter, as in previous studies of social decision-making ${ }^{34,87}$ (Figure S1). Participants 588 were instructed not to speak and wore a glove to hide any physical characteristics and to 589 ensure they were anonymous to one another. A second experimenter brought the confederate 590 to the other side of the door who was also instructed not to speak and wore a glove. 591 Participants only ever saw the gloved hand of the confederate, but they waved to each other

592 to make it clear there was another person there (Figure S1). The experimenter tossed a coin 593 to determine who picked a ball from the box first and then told the participants which roles 594 they had been assigned to, based on the ball that they picked. Unbeknownst to participants, 595 our procedure ensured that participants always ended up in the role of the person performing 596 the effort task inside the MRI scanner and they were led to believe the other participant would 597 be performing tasks outside of the scanner. We emphasised that the participant outside of the 598 scanner would only perform experimental tasks that would result in outcomes for themselves, 599 and would be unaware of the task performed by the participant inside the scanner so any 600 reward given would be anonymous. This procedure minimised as much as possible any 601 prosocial behaviour being due to social preferences of reciprocity ${ }^{88}$.

602 After finishing the task in the scanner, participants completed a short debriefing questionnaire 603 where they were probed as to whether they believed they were earning rewards for another 604 participant. Two participants reported a disbelief in the deception and were removed from 605 analysis.

\section{Statistical Analysis of Behavioural Data}

607 Analyses of behavioural data were performed using a combination of MATLAB (2019, The 608 MathWorks Inc.) and R (version 3.6.2) using RStudio ${ }^{89,90}$. For choices between the work and rest offers we coded choice as a binary outcome variable and ran a generalised linear mixed- 
bioRxiv preprint doi: https://doi.org/10.1101/2021.09.27.461936; this version posted September 28, 2021. The copyright holder for this preprint (which was not certified by peer review) is the author/funder, who has granted bioRxiv a license to display the preprint in perpetuity. It is made available under aCC-BY 4.0 International license.

610 effects model (GLMM) using the glmer function from the Ime4 package ${ }^{91}$. The model included

611 fixed effects of recipient, effort (squared to mirror the computational model results), reward,

612 and all interactions, as well as a subject-level random intercept. Squared effort and reward

613 were z-scored before being entered into the model. We exponentiated the resulting

614 standardised coefficients and standard error to generate odds ratios and their $95 \%$ confidence

615 intervals. Due to the non-normal distribution of the $K$ parameters, we compared discounting

616 for self and other using a non-parametric Wilcoxon two-sided signed rank test and generated

617 a standardised effect size $(r)$ for this difference using the wilcox_effsize function from the

618 rstatix package ${ }^{92}$.

619 For analysis of force exerted following a choice to work, we normalised participants' force as

620 a proportion of their maximum to account for between-subject variability in force exerted and 621 calculated the area under the curve for the 3 second window in which they exerted force. We 622 ran a linear mixed-effects model (LMM) that predicted normalised force with fixed effects of 623 recipient, effort level $(2,3,4,5,6)$, reward level $(2,3,4,5,6)$, and all interactions, plus a 624 subject-level random intercept. For both the GLMM on choices and LMM on force, we fit the 625 models by maximum likelihood and tested the fixed effects for statistical significance using 626 parametric bootstrapping (1000 simulations) with the mixed function from the afex package ${ }^{93}$. 627 We used type II tests meaning the significance of a variable was tested by comparing the full 628 model with the next most complex model that does not include that variable. For 629 completeness, we also report $Z$ statistics for the GLMM of choices and $\chi^{2}$ statistics for both 630 models from these comparisons (Table S1 \& S2).

\section{Questionnaire of Cognitive and Affective Empathy.}

632 Before the testing session, participants completed an online pre-testing questionnaire. The 633 questionnaire aimed to measure individual levels of empathy that might influence prosocial 634 behaviour. Empathy is the ability to vicariously experience and understand the affect of other 635 people ${ }^{36,94}$. This ability modulates people's social behaviour and is therefore critical to social 636 cognition and social decision-making. The Questionnaire of Cognitive and Affective Empathy 637 (QCAE) measures two dimensions of empathy cognitive and affective ${ }^{62}$. Items in the QCAE 638 corresponded to measures of cognitive empathy (such as I can easily work out what another 639 person might want to talk about) or affective empathy (I am happy when I am with a cheerful 640 group and sad when the others are glum). Participants rated how much each item applied to 641 them using a 4-point Likert scale from strongly agree to strongly disagree ${ }^{62}$. We used Pearson 642 correlations to test the link between QCAE scores and multivariate representations of 
643 prosocial effort in ACCg and compared correlations using the paired.r function from the psych 644 package ${ }^{95}$.

\section{Computational Modelling of Behavioural Data.}

646 For modelling of choice behaviour using trial-by-trial updates, we evaluated a number of

647 plausible models based on past research on effort discounting ${ }^{18-20,34}$. Models were fitted using 648 maximum likelihood estimation using the MATLAB function fmincon ${ }^{9,34}$ (Supplementary 649 Methods). For formal model comparison, we report the Bayesian information criterion (BIC) 650 based on the log-likelihood. The winning model was a three-parameter model with separate 651 discount $(K)$ parameters for self and other trials and a single temperature parameter. Discount 652 parameters $(K s)$ were bounded between 0 and 1.5 to ensure parameters reflected a sensible 653 range of behaviour in the task. We conducted both parameter recovery (Figure 2E) and model 654 identifiability to confirm the robustness of our model (see Supplementary Methods and Figure 655 S3).

\section{Imaging Methods}

657 Scanning was conducted in a Siemens Prisma 3-Tesla MRI scanner to acquire T2*-weighted 658 echo planar imaging (EPI) volumes with a BOLD contrast BOLD. EPI volumes were acquired 659 at a 30 degree ascending oblique angle to the AC-PC line. The angle chosen decreased the 660 impact of susceptibility artefacts in the orbitofrontal cortex, a method validated in previous 661 studies ${ }^{96}$. Acquisition parameters were as follows: voxel size $2 \times 2 \times 2,1 \mathrm{~mm}$ gap; TE $=30$ $662 \mathrm{~ms}$; repetition time $=1254 \mathrm{~ms}$; flip angle $=90^{\circ}$; field of view $=2.16 \mathrm{~mm}$. A magnetization 663 prepared rapid gradient echo (MPRAGE) sequence with 192 slices was used to obtain the 664 structural scan (slice thickness $=1 \mathrm{~mm}$; TR = $1900 \mathrm{~ms} ;$ TE $=3.97 \mathrm{~ms}$; field of view = $192 \mathrm{~mm}$ $665 \times 192 \mathrm{~mm}$; voxel size $=1 \times 1 \times 1 \mathrm{~mm}$ resolution).

\section{Imaging pre-processing and analyses}

667 Data were pre-processed and analysed using SPM12 (Wellcome Department of Imaging 668 Neuroscience, Institute of Neurology) and a standard pre-processing pipeline. Images were 669 realigned and unwarped using a fieldmap and co-registered to the participant's own 670 anatomical image. The anatomical image was processed using a unified segmentation 671 procedure combining segmentation, bias correction, and spatial normalization to the MNI 672 template using the New Segment procedure ${ }^{97}$. The same normalisation parameters were then 
bioRxiv preprint doi: https://doi.org/10.1101/2021.09.27.461936; this version posted September 28, 2021. The copyright holder for this preprint (which was not certified by peer review) is the author/funder, who has granted bioRxiv a license to display the preprint in perpetuity. It is made available under aCC-BY 4.0 International license.

673 used to normalise the EPI images, which were then spatially smoothed using an isotropic

674 Gaussian kernel at $8 \mathrm{~mm}$ full-width at half-maximum.

Imaging design: multivariate analysis

676 Representational similarity analysis (RSA) of fMRI data was performed using SPM12 and the

677 RSA toolbox ${ }^{54}$. We estimated voxel activity patterns time-locked to the offer cue for each effort,

678 reward and recipient combination. Both the hypothesis-driven $\mathrm{ROI}$ analysis and searchlight

679 analysis were based on smoothed data ${ }^{98}$. In addition, the GLM modelled the onset of force

680 exertion and the onset of the outcome, the break periods, as well as 6 motion regressors.

681 GLMs were inspected to ensure all events could be estimated independently from one another

682 (Figure S5). For both ROI analyses and whole-brain searchlight analyses we applied

683 multivariate noise normalisation to the voxel activity patterns to improve reliability ${ }^{54,66}$ and

684 calculated the correlation distance using the pdist function in Matlab (see Supplementary

685 materials for full RSA processing pipeline). The correlation distance metric was chosen as a

686 measure that is magnitude insensitive to the BOLD signal, and thus makes separate

687 predictions from the univariate trial-by-trial model-based analysis or by using alternative

688 distance metrics such as Euclidean distance ${ }^{57,66}$. As in previous RSA studies ${ }^{54,99-101}$ the

689 diameter of the searchlight sphere was $15 \mathrm{~mm}$ (approximately 100 voxels) and we used the

690 group level mask to define the volume for the searchlight analysis. The brain searchlight maps

691 were correlated with each behavioural RDM using Kendall's Tau-a to parallel the ROI analysis.

692 The resulting maps were minimally smoothed at $2 \mathrm{~mm}^{102}$ and then inputted into three second-

693 level flexible-factorial designs to examine effects of effort, subjective value and reward.

694 Formal conjunction analyses were run to determine the areas that responded across self/other

695 recipient conditions. Comparison analyses between self and other conditions ([-1 1] for other

$696>$ self or [1 -1] for self > other) were also run at each second-level design to reveal the areas

697 that responded specifically to one condition, yielding areas of domain-specific activation. For

698 searchlight analysis we report clusters significant at $p<0.05$, FWE-corrected for multiple

699 comparisons, with a cluster-defining threshold of $p<0.001$, uncorrected ${ }^{61}$. For $\mathrm{ROI}$ analysis we

700 tested whether correlations were significantly different from zero using non-parametric one-

701 sided Wilcoxon signed-rank tests across participants and tested whether correlations for self

702 were different from correlations for other with two-sided paired Wilcoxon signed-rank tests. All

703 reported comparisons survived FDR correction at $p<.05^{54}$. For one-sided tests this was across

70424 comparisons (4 brain RDMs, 3 model RDMs, 2 recipients) and for two-sided tests between

705 recipients, 12 comparisons (4 brain RDMs, 3 model RDMs). ROls were constructed using 
bioRxiv preprint doi: https://doi.org/10.1101/2021.09.27.461936; this version posted September 28, 2021. The copyright holder for this preprint (which was not certified by peer review) is the author/funder, who has granted bioRxiv a license to display the preprint in perpetuity. It is made available under aCC-BY 4.0 International license.

anatomical masks from regions of strong a priori interest, the $\mathrm{dmPFC} / \mathrm{dACC}^{18}$, anterior insula 18, ACCg $35,36,38,40,60$ and TPJ45,48.

\section{Imaging Design: Univariate analysis}

709 Three event types were used to construct regressors which would be convolved with Statistical

710 Parametric Mapping's canonical haemodynamic response function ${ }^{103}$. Onsets were modelled

711 using regressors for the choice phase, force phase, and outcome phase. Each regressor was

712 associated with a parametric modulator. The choice phase regressor was associated with the

713 parametric modulator of the subjective value difference of the chosen option, as in previous

714 work ${ }^{18}$, force with an effort required parametric modulator ( 0 if no effort or if chosen the level

715 of effort on offer), and reward with the outcome parametric modulator (the reward outcome

716 received on each trial). Each parametric modulator was separated by recipient (self or other).

717 The resulting design matrix had 12 columns: the first four represented self and other choices

718 as well as their subjective values (SVs), the next four represented the self and other force

719 exerted as well as their force (effort) parametric modulators, and the final four held self and

720 other outcomes and their parametric modulators. Additional regressors modelled the break

721 phase and missed trials in participants who had missed trials. First-level design matrices were

722 inspected to ensure the different parametric modulators could be estimated with

723 independence (Figure S6).

724 First-level contrast images built from the above-described design matrix focused on self and

725 other modulators of choice SV and force. These images were then inputted into two second-

726 level flexible-factorial designs that tested for neural regions that tracked the predicted SV

727 during the choice period and the level of effort during the force period. Conjunction analyses

728 were run to determine the areas that responded across self/other recipient conditions.

729 Comparison analyses between self and other conditions ( -11 for other $>$ self or $1-1$ for self $>$

730 other) were also run at each second-level design to reveal the areas that responded

731 specifically to one condition, yielding areas of domain-specific activation. Analyses were

732 reported at $p<.05$, family-wise error (FWE) corrected at the cluster level after thresholding at

$733 p<.001$ across the whole brain or at $p<.05$ small-volume corrected at the peak voxel level,

734 using anatomical masks from regions of strong a priori interest, the $\mathrm{dmPFC} / \mathrm{dACC}{ }^{18}$, anterior

735 insula ${ }^{18}, \mathrm{ACCg}^{35,36,38,40,60}$ and TPJ45,48.

\section{Data and code availability.}


737 All anonymized behavioural data and code used to generate the figures can be downloaded 738 at OSF (https://osf.io/tm45q during peer review please see 739 https://osf.io/tm45q/?view_only=a0e9171a075549e5946b6642334e1328).

740 All code used to run the computational modelling can be downloaded at OSF 741 (https://osf.io/tm45q during peer review please see 742 https://osf.io/tm45q/?view_only=a0e9171a075549e5946b6642334e1328). Unthresholded 743 statistical maps can be downloaded at NeuroVault (identifier to be added on publication).

\section{Acknowledgements}

745 This work was supported by a Medical Research Council Fellowship (MR/P014097/1), a Christ 746 Church Junior Research Fellowship, a Christ Church Research Centre Grant and a Jacobs 747 Foundation Research Fellowship to P. L. Lockwood; a Biotechnology and Biological Sciences 748 Research Council David Phillips Fellowship (BB/R010668/1) and a Wellcome Trust 749 Institutional Strategic Support Fund grant awarded to M. A. J. Apps; and a Wellcome Trust 750 Principal Fellowship to M. Husain; and the National Institute for Health Research Biomedical 751 Research Centre, Oxford, United Kingdom. The Wellcome Centre for Integrative 752 Neuroimaging is supported by core funding from the Wellcome Trust (203139/Z/16/Z).

\section{Author contributions}

Conceptualization P.L.L. and M.A.J.A; Methodology P.L.L., M.K.W., H.N., and M.A.J.A; Investigation, P.L.L., M.M-R, and A.A.; Formal analysis; P.L.L., M.K.W., H.N., J.C., and M.A.J.A; Writing - Original Draft, P.L.L, M.M-R., and M.A.J.A; Writing - Review \& Editing, P.L.L., M.K.W., H.N., M.M-R., A.A., J. C., M.H., and M.A.J.A; Funding Acquisition, P.L.L. M.A.J.A, and M. H.; Supervision, P.L.L. M.A.J.A, and M. H.

Declaration of interests

The authors declare no competing interests.

References

768 1. Camerer, C. F. Progress in behavioral game theory. Journal of Economic Perspectives 
770

771

772

773

774

775

776

777

778

779

780

781

782

783

784

785

786

787

788

789

790

791

792

793

794

2. Fehr, E. \& Fischbacher, U. Social norms and human cooperation. Trends in Cognitive Sciences 8, 185-190 (2004).

3. Post, S. G. Altuism, happiness, and health: it's good to be good. Int J Behav Med 12, 66-77 (2005).

4. Raposa, E. B., Laws, H. B. \& Ansell, E. B. Prosocial Behavior Mitigates the Negative Effects of Stress in Everyday Life. Clinical Psychological Science 4, 691-698 (2016).

5. Kosse, F. \& Tincani, M. M. Prosociality predicts labor market success around the world. Nature Communications 11, 5298 (2020).

6. Contreras-Huerta, L. S., Pisauro, A. \& Apps, M. A. Effort shapes social cognition and behaviour: A neuro-cognitive framework. Neuroscience \& Biobehavioral Reviews (2020).

7. Hare, T. A., Camerer, C. F., Knoepfle, D. T. \& Rangel, A. Value Computations in Ventral Medial Prefrontal Cortex during Charitable Decision Making Incorporate Input from Regions Involved in Social Cognition. Journal of Neuroscience 30, 583-590 (2010).

8. Imas, A. Working for the "warm glow": On the benefits and limits of prosocial incentives. Journal of Public Economics 114, 14-18 (2014).

9. Lockwood, P. L. et al. Prosocial apathy for helping others when effort is required. Nature Human Behaviour 1, s41562-017-0131 (2017).

10. Varazzani, C., San-Galli, A., Gilardeau, S. \& Bouret, S. Noradrenaline and dopamine neurons in the reward/effort trade-off: a direct electrophysiological comparison in behaving monkeys. J Neurosci 35, 7866-7877 (2015).

11. Krakauer, J. W., Ghazanfar, A. A., Gomez-Marin, A., MacIver, M. A. \& Poeppel, D. Neuroscience Needs Behavior: Correcting a Reductionist Bias. Neuron 93, 480-490 (2017). 
12. Lockwood, P. L., Apps, M. A. \& Chang, S. W. Is there a 'social'brain? Implementations and algorithms. Trends in Cognitive Sciences (2020).

13. Niv, Y. The primacy of behavioral research for understanding the brain. Behavioral Neuroscience (2021).

14. Apps, M. A., Grima, L. L., Manohar, S. \& Husain, M. The role of cognitive effort in subjective reward devaluation and risky decision-making. Scientific reports 5, 16880 (2015).

15. Hull, C. L. Principles of behavior: An introduction to behavior theory. (1943).

16. Kool, W. \& Botvinick, M. Mental labour. Nature human behaviour 2, 899-908 (2018).

17. Westbrook, A. \& Braver, T. S. Cognitive effort: A neuroeconomic approach. Cogn Affect Behav Neurosci (2015) doi:10.3758/s13415-015-0334-y.

18. Chong, T. T.-J. et al. Neurocomputational mechanisms underlying subjective valuation of effort costs. PLoS biology 15, e1002598 (2017).

19. Hartmann, M. N., Hager, O. M., Tobler, P. N. \& Kaiser, S. Parabolic discounting of monetary rewards by physical effort. Behavioural Processes 100, 192-196 (2013).

20. Klein-Flugge, M. C., Kennerley, S. W., Saraiva, A. C., Penny, W. D. \& Bestmann, S. Behavioral modeling of human choices reveals dissociable effects of physical effort and temporal delay on reward devaluation. PLoS Comput Biol 11, (2015).

21. Hart, E. E., Gerson, J. O., Zoken, Y., Garcia, M. \& Izquierdo, A. Anterior cingulate cortex supports effort allocation towards a qualitatively preferred option. Eur J Neurosci 46, 1682-1688 (2017).

22. Hart, E. E., Blair, G. J., O’Dell, T. J., Blair, H. T. \& Izquierdo, A. Chemogenetic Modulation and Single-Photon Calcium Imaging in Anterior Cingulate Cortex Reveal a Mechanism for Effort-Based Decisions. J. Neurosci. 40, 5628-5643 (2020). 
23. Hu, Y., Wingerden, M. van, Sellitto, M., Schäble, S. \& Kalenscher, T. Anterior Cingulate Cortex Lesions Abolish Budget Effects on Effort-Based Decision-Making in Rat Consumers. J. Neurosci. 41, 4448-4460 (2021).

24. Pessiglione, M., Vinckier, F., Bouret, S., Daunizeau, J. \& Le Bouc, R. Why not try harder? Computational approach to motivation deficits in neuro-psychiatric diseases. Brain 141, 629-650 (2018).

25. Walton, M. E., Kennerley, S. W., Bannerman, D. M., Phillips, P. E. M. \& Rushworth, M. F. S. Weighing up the benefits of work: Behavioral and neural analyses of effortrelated decision making. Neural Networks 19, 1302-1314 (2006).

26. Croxson, P. L., Walton, M. E., O’Reilly, J. X., Behrens, T. E. J. \& Rushworth, M. F. S. Effort-Based Cost-Benefit Valuation and the Human Brain. Journal of Neuroscience 29, 4531-4541 (2009).

27. Holroyd, C. B. \& McClure, S. M. Hierarchical control over effortful behavior by rodent medial frontal cortex: A computational model. Psychol Rev 122, (2015).

28. Lopez-Gamundi, P. et al. The neural basis of effort valuation: A meta-analysis of functional magnetic resonance imaging studies. bioRxiv (2021).

29. Soutschek, A., Kang, P., Ruff, C. C., Hare, T. A. \& Tobler, P. N. Brain Stimulation Over the Frontopolar Cortex Enhances Motivation to Exert Effort for Reward. Biol Psychiatry 84, 38-45 (2018).

30. Vassena, E. et al. Overlapping neural systems represent cognitive effort and reward anticipation. PLoS One 9, (2014).

31. Verguts, T., Vassena, E. \& Silvetti, M. Adaptive effort investment in cognitive and physical tasks: a neurocomputational model. Frontiers in Behavioral Neuroscience $\mathbf{9}$, $57(2015)$. 
32. Le Heron, C., Apps, M. A. J. \& Husain, M. The anatomy of apathy: a neurocognitive framework for amotivated behavior. Neuropsychologia (2017) doi:10.1016/j.neuropsychologia.2017.07.003.

33. Contreras-Huerta, L. S., Lockwood, P. L., Bird, G., Apps, M. A. \& Crockett, M. J. Prosocial behavior is associated with transdiagnostic markers of affective sensitivity in multiple domains. Emotion (2020).

34. Lockwood, P. L. et al. Aging Increases Prosocial Motivation for Effort. Psychological Science 32, 668-681 (2021).

35. Apps, M. A. J., Rushworth, M. F. S. \& Chang, S. W. C. The Anterior Cingulate Gyrus and Social Cognition: Tracking the Motivation of Others. Neuron 90, 692-707 (2016).

36. Lockwood, P. L. The anatomy of empathy: Vicarious experience and disorders of social cognition. Behav Brain Res 311, 255-266 (2016).

37. Chang, S. W. C., Gariepy, J.-F. \& Platt, M. L. Neuronal reference frames for social decisions in primate frontal cortex. Nature Neuroscience 16, 243-250 (2013).

38. Apps, M. A. J. \& Ramnani, N. The Anterior Cingulate Gyrus Signals the Net Value of Others' Rewards. The Journal of Neuroscience 34, 6190-6200 (2014).

39. Apps, M. A., Lesage, E. \& Ramnani, N. Vicarious reinforcement learning signals when instructing others. Journal of Neuroscience 35, 2904-2913 (2015).

40. Lockwood, P. L., Apps, M. A., Roiser, J. P. \& Viding, E. Encoding of vicarious reward prediction in anterior cingulate cortex and relationship with trait empathy. Journal of Neuroscience 35, 13720-13727 (2015).

41. Lockwood, P. L. et al. Neural mechanisms for learning self and other ownership. Nature Communications 9, 4747 (2018).

42. Lamm, C., Rütgen, M. \& Wagner, I. C. Imaging empathy and prosocial emotions. Neurosci Lett 693, 49-53 (2019). 
43. Zaki, J. Empathy: A Motivated Account. Psychological bulletin 59, 257-72 (2014).

44. Crockett, M. J., Siegel, J. Z., Kurth-Nelson, Z., Dayan, P. \& Dolan, R. J. Moral transgressions corrupt neural representations of value. Nat Neurosci 20, 879-885 (2017).

45. Le Bouc, R. \& Pessiglione, M. Imaging Social Motivation: Distinct Brain Mechanisms Drive Effort Production during Collaboration versus Competition. J. Neurosci. 33, 15894 (2013).

46. Morishima, Y., Schunk, D., Bruhin, A., Ruff, C. C. \& Fehr, E. Linking Brain Structure and Activation in Temporoparietal Junction to Explain the Neurobiology of Human Altruism. Neuron 75, 73-79 (2012).

47. Obeso, I., Moisa, M., Ruff, C. C. \& Dreher, J.-C. A causal role for right temporoparietal junction in signaling moral conflict. eLife 7, e40671 (2018).

48. Ruff, C. C. \& Fehr, E. The neurobiology of rewards and values in social decision making. Nat Rev Neurosci 15, 549-562 (2014).

49. Seltzer, B. \& Pandya, D. N. Frontal lobe connections of the superior temporal sulcus in the rhesus monkey. J. Comp. Neurol. 281, 97-113 (1989).

50. Vogt, B. A. \& Pandya, D. N. Cingulate cortex of the rhesus monkey. 2. Cortical afferents. Journal of Comparative Neurology 262, 271-289 (1987).

51. Kriegeskorte, N. \& Kievit, R. A. Representational geometry: integrating cognition, computation, and the brain. Trends in Cognitive Sciences 17, 401-412 (2013).

52. Palminteri, S., Wyart, V. \& Koechlin, E. The Importance of Falsification in Computational Cognitive Modeling. Trends in Cognitive Sciences 21, 425-433 (2017).

53. Lockwood, P. L. \& Klein-Flügge, M. C. Computational modelling of social cognition and behaviour - a reinforcement learning primer. Social Cognitive and Affective Neuroscience (2020). 
893

894

895

896

897

898

899

900

901

902

903

904

905

906

907

908

909

910

911

912

913

914

915

916

54. Nili, H. et al. A toolbox for representational similarity analysis. PLoS Comput Biol 10, e1003553 (2014).

55. Love, B. C. The Algorithmic Level Is the Bridge Between Computation and Brain. Topics in Cognitive Science 7, 230-242 (2015).

56. Dimsdale-Zucker, H. R. \& Ranganath, C. Representational Similarity Analyses. in Handbook of Behavioral Neuroscience vol. 28 509-525 (Elsevier, 2018).

57. Popal, H., Wang, Y. \& Olson, I. R. A Guide to Representational Similarity Analysis for Social Neuroscience. Social Cognitive and Affective Neuroscience 14, 1243-1253 (2019).

58. Wittmann, M. K., Lockwood, P. L. \& Rushworth, M. F. S. Neural Mechanisms of Social Cognition in Primates. Annual Review of Neuroscience 41, 99-118 (2018).

59. Maldjian, J. WFU PickAtlas User Manual v2 . 4. 1-13.

60. Neubert, F.-X., Mars, R. B., Sallet, J. \& Rushworth, M. F. S. Connectivity reveals relationship of brain areas for reward-guided learning and decision making in human and monkey frontal cortex. Proceedings of the National Academy of Sciences 201410767 (2015).

61. Eklund, A., Nichols, T. E. \& Knutsson, H. Cluster failure: Why fMRI inferences for spatial extent have inflated false-positive rates. Proc Natl Acad Sci USA 113, 7900 (2016).

62. Reniers, R. L. E. P., Corcoran, R., Drake, R., Shryane, N. M. \& Völlm, B. a. The QCAE: a Questionnaire of Cognitive and Affective Empathy. Journal of personality assessment 93, 84-95 (2011).

63. Batson, C. D. Altruism and prosocial behavior. in The handbook of social psychology, 4th edition (New York: McGraw-Hill., 1998). 
64. Decety, J., Bartal, I. B.-A., Uzefovsky, F. \& Knafo-Noam, A. Empathy as a driver of prosocial behaviour: highly conserved neurobehavioural mechanisms across species. Philos. Trans. R. Soc. Lond., B, Biol. Sci. 371, (2016).

65. Lockwood, P. L., Ang, Y.-S., Husain, M. \& Crockett, M. J. Individual differences in empathy are associated with apathy-motivation. Scientific Reports 7, 17293 (2017).

66. Walther, A. et al. Reliability of dissimilarity measures for multi-voxel pattern analysis. NeuroImage 137, 188-200 (2016).

67. Rudebeck, P. H., Buckley, M. J., Walton, M. E. \& Rushworth, M. F. S. A role for the macaque anterior cingulate gyrus in social valuation. Science 313, 1310-1312 (2006).

68. Carrillo, M. et al. Emotional Mirror Neurons in the Rat's Anterior Cingulate Cortex. Current Biology 29, 1301-1312.e6 (2019).

69. Han, Y. et al. Bidirectional cingulate-dependent danger information transfer across rats. PLoS Biol 17, e3000524 (2019).

70. Hillman, K. L. \& Bilkey, D. K. Neural encoding of competitive effort in the anterior cingulate cortex. Nature Neuroscience 15, (2012).

71. Hill, M. R., Boorman, E. D. \& Fried, I. Observational learning computations in neurons of the human anterior cingulate cortex. Nature Communications 7, (2016).

72. Basile, B. M., Schafroth, J. L., Karaskiewicz, C. L., Chang, S. W. C. \& Murray, E. A. The anterior cingulate cortex is necessary for forming prosocial preferences from vicarious reinforcement in monkeys. PLoS Biol 18, e3000677 (2020). system necessary for learning to reward others? PLOS Biology 18, e3000735 (2020). amygdala coordination in other-regarding decision preference. Nature neuroscience 23, 565-574 (2020). 
942

943

944

945

946

947

948

949

950

951

952

953

954

955

956

957

958

959

960

961

962

963

964

965

75. Morelli, S. A., Sacchet, M. D. \& Zaki, J. Common and distinct neural correlates of personal and vicarious reward: A quantitative meta-analysis. Neuroimage 112, 244-253 (2015).

76. Hauser, T. U., Eldar, E. \& Dolan, R. J. Separate mesocortical and mesolimbic pathways encode effort and reward learning signals. Proc Natl Acad Sci U S A 114, E7395-E7404 (2017).

77. Müller, T., Klein-Flügge, M. C., Manohar, S. G., Husain, M. \& Apps, M. A. J. Neural and computational mechanisms of momentary fatigue and persistence in effort-based choice. Nat Commun 12, 4593 (2021).

78. Westbrook, A., Lamichhane, B. \& Braver, T. The subjective value of cognitive effort is encoded by a domain-general valuation network. Journal of Neuroscience 39, 3934 3947 (2019).

79. Kennerley, S. W., Dahmubed, A. F., Lara, A. H. \& Wallis, J. D. Neurons in the Frontal Lobe Encode the Value of Multiple Decision Variables. Journal of Cognitive Neuroscience 21, 1162-1178 (2009).

80. Elston, T. W. \& Bilkey, D. K. Anterior Cingulate Cortex Modulation of the Ventral Tegmental Area in an Effort Task. Cell Reports 19, 2220-2230 (2017).

81. Hamid, A. A. et al. Mesolimbic dopamine signals the value of work. Nature Neuroscience 19, 117-126 (2016).

82. Kroemer, N. B. et al. Balancing reward and work: anticipatory brain activation in NAcc and VTA predict effort differentially. Neuroimage 102, 510-519 (2014).

83. Kurniawan, I. T., Guitart-Masip, M., Dayan, P. \& Dolan, R. J. Effort and Valuation in the Brain: The Effects of Anticipation and Execution. Journal of Neuroscience 33, 6160-6169 (2013). 
84. Fehr, E. \& Camerer, C. F. Social neuroeconomics: the neural circuitry of social preferences. Trends in Cognitive Sciences 11, 419-427 (2007).

968

969

970

971

972

973

974

975

976

977

978

979

980

981

982

983

984

985

986

987

988

989

990

85. King-Casas, B. et al. Getting to know you: Reputation and trust in a two-person economic exchange. Science 308, 78-83 (2005).

86. Tomlin, D. et al. Agent-specific responses in the cingulate cortex during economic exchanges. Science 312, 1047-1050 (2006).

87. Crockett, M. J., Kurth-nelson, Z., Siegel, J. Z., Dayan, P. \& Dolan, R. J. Harm to others outweighs harm to self in moral decision making. Proceedings of the National Academy of Sciences 112, 201424572 (2015).

88. Fehr, E. \& Schmidt, K. M. Chapter 8 The Economics of Fairness, Reciprocity and Altruism - Experimental Evidence and New Theories. in Handbook of the Economics of Giving, Altruism and Reciprocity (eds. Kolm, S.-C. \& Ythier, J. M.) vol. 1 615-691 (Elsevier, 2006).

89. R Core Team. R: A language and environment for statistical computing. R Foundation for Statistical Computing. (2017).

90. RStudio Team. RStudio: Integrated Development for R. RStudio, Inc. (2015).

91. Bates, D., Mächler, M., Bolker, B. \& Walker, S. Fitting Linear Mixed-Effects Models Using lme4. Journal of Statistical Software 67, 1-48 (2015).

92. Kassambara, A. rstatix: Pipe-Friendly Framework for Basic Statistical Tests. R package version 0.5.0. (2020).

93. Singmann, H., Bolker, B., Westfall, J., Aust, F. \& Ben-Shachar, M. S. afex: Analysis of Factorial Experiments. R package version 0.25-1. (2019).

94. Singer \& Lamm, C. The social neuroscience of empathy. Annals of the New York Academy of Sciences 1156, 81-96 (2009).

95. Revelle, W. Package 'psych'. The Comprehensive R Archive Network (2015). 
991

992

993

994

995

996

997

998

999

1000

1001

1002

1003

1004

1005

1006

1007

1008

1009

96. Deichmann, R., Gottfried, J. A., Hutton, C. \& Turner, R. Optimized EPI for fMRI studies of the orbitofrontal cortex. Neuroimage 19, 430-441 (2003).

97. Ashburner, J. \& Friston, K. J. Unified segmentation. Neuroimage 26, 839-851 (2005).

98. Hendriks, M. H. A., Daniels, N., Pegado, F. \& Op de Beeck, H. P. The Effect of Spatial Smoothing on Representational Similarity in a Simple Motor Paradigm. Front. Neurol. 0, (2017).

99. Bang, D., Ershadmanesh, S., Nili, H. \& Fleming, S. M. Private-public mappings in human prefrontal cortex. Elife 9, e56477 (2020).

100. Baram, A. B., Muller, T. H., Nili, H., Garvert, M. M. \& Behrens, T. E. J. Entorhinal and ventromedial prefrontal cortices abstract and generalize the structure of reinforcement learning problems. Neuron 109, 713-723.e7 (2021).

101. Park, S. A., Miller, D. S., Nili, H., Ranganath, C. \& Boorman, E. D. Map Making: Constructing, Combining, and Inferring on Abstract Cognitive Maps. Neuron 107, 1226-1238.e8 (2020).

102. Flandin, G. \& Friston, K. J. Analysis of family-wise error rates in statistical parametric mapping using random field theory. Human brain mapping 40, 2052-2054 (2019).

103. Penny, W. D., Friston, K. J., Ashburner, J. T., Kiebel, S. J. \& Nichols, T. E. Statistical parametric mapping: the analysis of functional brain images. (Elsevier, 2011). 